\title{
Xanthogranulomatous Pyelonephritis A Review and Update of
}

\section{the Literature}

\section{Anthony Kodzo-Grey Venyo}

North Manchester General Hospital, Department of Urology Manchester, M8 5RB, United Kingdom.

\section{ABSTRACT}

Xanthogranulomatous pyelonephritis (XGP) is a rare chronic destructive granulomatous inflammatory process that affects sporadically the parenchyma of the kidney and the disease tends to be associated in many cases with long-term urinary tract obstruction, urinary tract infection and also in cases with calculi within the kidney. XGP does affect females more commonly in comparison with males, it does affect all age groups including newly born up to the elderly. Majority of the patients tend to be symptomatic and some of the symptoms could include: pyrexia, flank / loin / abdominal pain, palpable mass in loin/abdomen/costovertebral region, weight loss, visible haematuria. There may be associated diabetes mellitus, obesity, or immune deficiency. There may be anaemia and leucocytosis upon blood tests. Urine cultures may grow Escherichia coli, or proteus but in other situations the urine culture could be negative. Ultrasound scan of renal tract, CT and MRI scan of abdomen and pelvis tend to be undertaken in the assessments of patients. CT scan has globally been the establishment of radiology imaging diagnosis. Radiology imaging may demonstrate focal or diffuse XGP but the diffuse form is more common. It may reveal multiple lowattenuated cystic masses in the kidney, calculi in the kidney, hydronephrosis / dilated calyces / bear's paw appearance in some cases. Macroscopy examination of the specimen of the kidney would tend to show multiple yellow nodules around calyces, and the lesion may form a mass or be infiltrative. Pathology examination of specimens of XGP would tend to show granulomatous inflammatory infiltrate that consists of neutrophils, lymphocytes, plasma cells, xanthomatous histiocytes, as well as multi-nucleated giant cells. Immunohistochemistry staining may show positive staining for CD68. Some of the differential diagnoses include: clear cell carcinoma of the kidney, papillary renal cell carcinoma, sarcomatoid renal cell carcinoma, leiomyosarcoma, malakoplakia of kidney, megalocystic interstitial nephritis, and renal replacement lipomatosis. Majority of diffuse cases have been treated by nephrectomy and antibiotics and some focal cases have been treated by partial nephrectomy and antibiotics but on very rare occasions cases have been treated by drainage of the abscess with biopsy and in conjunction with antibiotics. Percutaneous nephrostomy has also been undertaken pre-operatively to decompress the kidney by draining the abscess in the occasional case.

Keywords: Xanthogranulomatous pyelonephritis; Nephrectomy; hydronephrosis, calculi; antibiotics; CD68; Bear's paw appearance; renal cell carcinoma; CT scan; Ultrasound scan; Histopathology; xanthomatous histiocytes.

Crossref Doi: https://doi.org/10.36437/irmhs.2019.2.6.A 


\section{Introduction}

It has been iterated that Xanthogranulomatous pyelonephritis (XGP) was first described by Schlagenhaufer in $1916 \quad[1]$ and that Xanthogranolomatous pyelonephritis (XGP) is an uncommon, serious, chronic inflammatory disorder that affects the kidney and it is typified by a destructive mass which does invade the parenchyma of the kidney [2] [3]. It has been documented that XGP tends commonly to be associated with Proteus infection or Escherichia coli infection [2]. Other organisms including pseudomonas could be cultured in the urine. It has also been noted that in cases of $\mathrm{XGP}$, the kidney tends to be non-functional and that in majority of cases of XGP, the inflammatory process tends to be diffuse; nevertheless, up to $20 \%$ of cases of XGP tend to be focal [2] Less than 500 cases of Xanthogranulomatous pyelonephritis to the knowledge of the author have been reported in view of this it is likely that many clinicians may be unfamiliar with the biological behaviour and management of the disease because they have not encountered the disease before. The ensuing review and update article on Xanthogranulomatous pyelonephritis is divided into two parts (A) Overview and (B) Miscellaneous narrations and discussions from some case reports, case series and studies related to Xanthogranulomatous pyelonephritis.

\section{Aim}

To review and update the literature on Xanthogranulomatous pyelonephritis.

\section{Method}

Internet data bases were searched including Goggle; Google Scholar; Yahoo and PUBMED. The search words that were used included: Xanthogranulomatous pyelonephritis, Xanthogranulomatous inflammation of kidney. Forty five references were identified which were used to write the article which has been divided into two parts (A) Overview and (B) Miscellaneous narrations from some case reports, case series and studies related to Xanthogranulomatous pyelonephritis.

\section{Results}

\section{(A)Overview}

\section{Definition and General Comments}

- It has been stated that Xanthogranulomatous pyelonephritis is an uncommon, severe, and atypical type of chronic pyelonephritis. Which tends to emanate from (b) infection which has been caused by Eschericia Coli (E Coli) or Proteus, or (b) stones; nevertheless, Xanhogranulomathous pyelonephritis does mimic malignant tumour of the kidney and because of this semblance the correct preoperative diagnosis of the disease has been unusual. [4]; [5]; [6].

- It has been iterated that pathology examination of specimens of xanthogranulomatous pyelonephritis does characterize the lesion by presence of foamy histiocytes that replace the parenchyma of the kidney [4].

- It has been documented that a high index of suspicion for Xanthogranulomatous pyelonephritis is necessitated in order to establish a pre-operative diagnosis of the disease [4] [7], and that undertaking of intra-operative urine culture could be beneficial with regard to the diagnosis of the disease [4] [8].

\section{Clinical Features / Presentation}

- It has been stated that Xanthogranulomatous pyelonephritis is a destructive inflammatory process which could emanate as a complication of chronic pyelonephritis [4].

- It has been iterated that Xanthogranolomatous pyelonephritis usually tends to be a unilateral renal disease which does affect people that are generally older than 40 years as well as that it tends to 
be more common in females in that two thirds of cases of Xanthogranulomatous pyelonephritis does affect females [4].

- It is worth pointing out that Xanthogranulomatous pyelonephritis does affect people of all ages including sporadic cases affecting children and the elderly.

- It has been documented that Xanthogranulomatous pyelonephritis tends also to be associated with pelvicalyceal obstruction as well as ulceration [4].

- It has been reported that Xanthogranulomatous pyelonephritis does manifest in association with squamous cell carcinoma of the kidney, [4]; [9]; and with renal cell carcinoma [4] [10].

- Xanthogranulomatous pyelonephritis may present with non-specific symptoms some of which include: loin pain, palpable mass in loin/upper quadrant of abdomen, visible haematuria, weight loss, sudden onset of severe abdominal / loin pain

\section{Clinical Examination Findings}

- The general and systematic examinations could be normal but there could be evidence of pallor in cases of XGP associated with visible haematuria.

- $\quad$ There may be tenderness in the loin / lumbar region / costovertebral angle.

- There may be a palpable mass in the abdomen usually in the loin / lumbar region / costovertebral angle / upper outer quadrant of the abdomen.

- The findings would be non-specific and would require to be investigated initially by radiology imaging apart from general laboratory investigations.

\section{Laboratory Investigations}

\section{Urine}

- Urinalysis, urine microscopy and culture are general investigations that tend to be undertaken in all cases of XGP. There could be evidence of non-visible or visible haematuria. The urine culture may grow Escherichia Coli or Proteus or pseudomonas. On some occasions there may be evidence of previous E Coli or proteus urinary tract infections. Based upon the culture and sensitivity results of the urine test, appropriate antibiotics treatment would be commenced to improve upon the general condition of the patient.

- There may not be any evidence of urinary tract infection during the acute admission on some occasions.

\section{Blood Tests}

\section{Haematology Blood Tests}

- Routine full blood count, erythrocyte sedimentation rate (ESR), and coagulation screen are routine tests that tend to be undertaken in the general assessment of patients who have XGP and at times the results could be normal.

- A patient who has had visible haematuria could be anaemic with a low haemoglobin level that would require treatment to improve upon the general condition of the patient.

- The erythrocyte sedimentation rate (ESR) could be raised.

\section{Biochemistry Blood Tests}

- Serum urea, creatinine, estimated glomerular filtration rate, electrolytes, blood glucose, and liver function tests are general tests that tend to be undertaken in the general assessments of patients who have XGP and the results could be normal but in some cases there would be impaired renal function that would need to be further investigated and managed accordingly.

- In cases of a unilateral diffuse XGP and an already damaged contralateral kidney due to a previous and different disease there could be impaired renal function.

- If there is impairment of renal function and radiology imaging does show hydronephrosis / abscess then insertion of per-cutaneous nephrostomy would drain 
the pus as well help improve the renal function.

\section{Radiology Investigations}

\section{Plain Abdominal $x$-ray and chest $x$-ray}

- Chest x-ray and abdominal x-ray may be undertaken immediately some patients present with loin/upper abdominal/costovertebral pain and difficulty in breathing plus a mass in the abdomen. The chest x-ray could show a raised diaphragm and atelectasis due to pressure effect from an irregular large upper pole renal lesion.

- The abdominal x-ray may also show presence of a staghorn calculus in the affected kidney or multiple calculi within the affected kidney and dilated calyces.

\section{Ultrasound Scan}

- Ultrasound scan of abdomen and renal tract may show an enlarged kidney and a staghorn calculus or many calculi in the kidney and the calyces would tend to be dilated as well as tend to contain low-level echoes which does represent debris or pus.

- XGP does not have any specific ultrasound scan features but the diagnosis could be suggested by the finding of thinning of the parenchyma of the kidney and hydronephrosis, ultrasound scan finding of chronic obstructive uropathy which has been caused by kidney stones, echoes within the dilated renal collecting system and perinephric collection of fluid [11].

- Ultrasound scan could also demonstrate a large roundish hypo-echoic solid looking mass in one pole of the kidney in a case of focal XGP which would tend to mimic a malignant tumour of the kidney and the finding would not be specific to diagnose XGP.

\section{Computed Tomography (CT) Scan}

- Some of the CT scan findings in unilateral XGP include unilateral enlargement of the kidney and inflammation of the kidney as well as multiple areas of low-attenuation due to dilated renal calyces and pus-filled cavities that have replaced destroyed parenchyma of the kidney [12].

- In XGP CT scan does show loss of the normal outline of the kidney and enlargement with paradoxical contracted renal pelvis. The calyces tend to be dilated which do give multi-loculated appearance that has been likened to the paw print of a bear which has been referred to as bear's paw sign. [3] On other occasions, there tends to be a perinephric extension with thickening of the Gerota's fascia as well as calcification could be delineated.

\section{Magnetic Resonance Imaging Scan}

- It has been stated that the MRI scan appearances of XGP do mirror the heterogeneous nature of the mass that has solid and cystic components encompassing a central staghorn calculus and that the signal tends to be heterogeneous on all sequences.

\section{Angiography}

- On rare occasions when the renal vein and IVC are involved by XGP then angiography tends to be undertaken for further assessment in the planning the surgical intervention of such a patient after multidisciplinary team discussion between the urologist, the radiologist and the vascular surgeon.

\section{Diagnosis}

- Diagnosis of XGP tends to be confirmed by pathology examination of nephrectomy specimens and also the pathology features of renal biopsy specimens could help establish the diagnosis of XGP. Even though the radiology imaging features of the renal lesion sometimes may be suggestive of XGP, 
quite often XGP cannot be fully differentiated from a malignant tumour of the kidney therefore tissue diagnosis is required. Additionally few cases of XGP have been found contemporaneously in association with a malignant tumour of the kidney.

- Macroscopy examination of XGP could reveal a large yellowish tissue that is associated with many areas of necrosis as well as haemorrhagic areas which would tend to simulate carcinoma or a malignant tumour of the kidney.

- Microscopy examination of the nephrectomy specimen or renal biopsy specimen would demonstrate lipid-laden foamy macrophages that are associated with both acute-phase inflammatory cells or chronic inflammatory cells. There may also be visualised Liesegang rings within the specimen on some occasions.

\section{Treatment}

- Generally XGP has been managed successfully by either nephrectomy for diffuse XGP and partial nephrectomy for some cases of focal XGP in combination with utilization of appropriate antibiotic treatment.

- A case of focal XGP in a child has been treated successfully by open drainage of the abscess collection in the kidney plus biopsy of the kidney specimen in combination with utilization of antibiotics with successful outcome.

- The surgical operation of nephrectomy was made easier in a case where initially percutaneous nephrostomy was undertaken to drain the pus within the kidney which allowed the kidney mass to decrease in size and to drain the infecting organism to avoid sepsis during the subsequent nephrectomy procedure which was undertaken in combination with utilization of antibiotics.
- Conservative methods have not been explored generally for various reasons including nephrectomy was undertaken with a provisional diagnosis of likely renal tumour and the XGP diagnosis was incidental and also even if XGP was suspected one could not exclude malignancy.

- Perhaps the possibility of insertion of percutaneous drain to decompress the kidney and drain the pus in combination with utilization of antibiotics and observation needs to be tried in situations where there is enough normal functioning kidney tissue to see if the patient would respond well and if not then nephrectomy would follow. On the whole due to the presence of large staghorn calculi and very small normal functioning renal parenchyma in the affected kidney a nephrectomy would be an easier option of management for majority of patients.

- At the moment generally total nephrectomy has been the main standard of treatment for XGP unless in bilateral cases where partial nephrectomy has been undertaken with success [13].

\section{Macroscopic Pathology Features}

- It has been stated that upon gross examination of a kidney that has been involved by xanthogranulomatous pyelonephritis, multiple yellow nodules tend to be visualised around calyces that may form a mass and it could be infiltrative [4].

\section{Microscopic Pathology Examination Features}

- It has been documented that microscopic examination of specimen of the kidney affected by xanthogranulomatous pyelonephritis does show foamy histiocytes 
as well as rare multi-nucleated giant cells and inflammatory cells [4].

- Liesegang rings could also be visualised occasionally.

\section{Immunohistochemistry Studies Positive staining}

- CD68+ - It has been stated that immunohistochemistry staining of specimens taken from a kidney that has been affected by Xanthogranulomatous pyelonephritis does stain positively for CD68 [4].

\section{Differential Diagnoses}

Some of the documented differential diagnoses of Xanthogranulomatous pyelonephritis include [4]:

- Malakoplakia of the kidney - It has been stated that in Malakoplakia of the kidney, microscopic examination of the specimen of the kidney would tend to show MichaelisGutmann bodies [4].

- Clear cell carcinoma of the kidney - It has been iterated that microscopy examination of specimens of clear cell carcinoma of the kidney does show tumour cells that have clear cytoplasm that mimic histiocytes and which tend to be arranged in compact, tubulocystic, alveolar, or on rare occasions papillary patterns, as well as quite often the microscopic examination would show glassy hyaline globules and also usually nuclear grade 2 of higher than grade 2, chicken wire / delicate vasculature (which represent sinusoids near each packet of cells) tends to be commonly visualised [4].

- Renal replacement lipomatosis - It has been stated that in renal replacement lipomatosis microscopic examination of the kidney would tend to show an atrophic kidney parenchyma which has been replaced by fatty tissue and not xanthoma cells. [4]; [14].

\section{Outcome}

- Following treatment by nephrectomy combined with antibiotics treatment the outcome generally has been good.

- Following partial nephrectomy and antibiotic treatment for focal XGP the outcome has been good for the few patients who had undergone the procedure.

- Following open drainage and biopsy of the renal lesion which diagnosed XGP in combination with utilization of antibiotics the outcome has been good. Nevertheless, because majority of cases of XGP had provisionally been diagnosed as possible renal carcinomas radical nephrectomy has tended to be undertaken; nevertheless, if a radiology imaging diagnosis of XGP is made if the XGP is not too extensive and there is reasonable amount normal of renal parenchyma tissue then per-cutaneous drainage of the renal collection via nephrostomy / - drain can be undertaken initially with antibiotic treatment and if the patient recovers then the staghorn calculus could be treated by percutaneous nephrolithotomy using the same percutaneous nephrostomy tract but this suggestion is only conjectural and has not been reported to the knowledge of the author.

(B) Miscellaneous narrations and discussions from some case reports, case series and studies related to Xanthogranulomatous pyelonephritis. Quinn et al. [6] reported a retrospective review of 31 individual children that had xanthogranulomatous pyelonephritis based upon histopathology diagnosis of their disease between 1963 and 1999. Quinn et al. [6] summarized the results as follows:

- The mean follow-up was 8.2 years and the male to female ratio was 1:1.1

- The left kidney was affected in 26 individuals out of the 31 individuals affected by the disease. 
- The positive findings with regard to clinical examinations and investigations at the time of the initial presentations of the patients included:

- Fever in 16 children.

- Pyuria in 26 children.

- Positive urine culture in 16 children.

- A haemoglobin of less than $100 \mathrm{~g} / \mathrm{l}$ was found in 27 out of the 31 patients.

○ 15 patients out of 18 patients who were tested for erythrocyte sedimentation rate had erythrocyte sedimentation rate higher than $20 \mathrm{~mm}$ within the first hour.

$\circ$ Twenty six (26) children had renal calculi and this was associated with a large reduction of the function of the kidney that was affected by the XGP upon isotope renogram testing in 27 out of 29 children tested.

$\circ$ Hypertrophy of the contralateral kidney which had been demonstrated upon radiology imaging was observed in 17 out of the 31 patients.

Quinn et al. [6] concluded that increasing awareness of XGP should lead to the diagnosis being suspected pre-operatively.

Kuo et al. [7] undertook a comprehensive review of all nephrectomy patients who had a pre-operative diagnosis of pyelonephritis at the National Taiwan University Hospital from 1991 to 2008 with the pathology examination diagnosis of XGP to illustrate the clinical and the radiology imaging features of XGP. Kuo et al. [7] summated the results as follows:
- XGP had been diagnosed in 30 out of 160 nephrectomies that had been undertaken for pyelonephritis and this amounted to $18.6 \%$ of the patients.

- Out of the 30 patients who were diagnosed as having XGP, 25 that amounted to $83.3 \%$ of the patients were women and 20 that amounted to $66.7 \%$ of the patients were overweight with a body mass index greater than 23.

- The mean age of the patients was 55.17 years.

- The average level of the serum creatinine was $1.68 \mathrm{mg} / \mathrm{dl}$.

- The radiology imaging findings had included: renal calculi in $56.7 \%$ of the patients, staghorn calculi in $26.7 \%$ of the patients, as well as spread of the disease to the retroperitoneum, and psoas muscle in $33.3 \%$ of the patients.

- Escherichia coli (E. Coli) was the most predominant cultured pathogen which was found in $36.7 \%$ of the patients.

- The mortality of the two-stage surgical procedure was zero and morbidity did develop in 1 patient that amounted to $4.8 \%$ of the patients.

\section{Kuo et al. [7] made the ensuing conclusions:}

- The key regarding the accurate preoperative diagnosis is to keep in mind the risk factors such as: the age of the patient, the sex of the patient, and renal calculi.

- Clinicians should have a high index of suspicion for XGP in order to recognise the condition early as well as they should be familiar with the care of chronic kidney disease.

- The association between XGP and central obesity would warrant further research.

Apart from the conclusions of Kuo et al. [7] other things that could be beneficial to the management of XGP would include: Good control of the diabetes mellitus in patients who have diabetes mellitus, 
availability of a well-trained interventional radiologist who can undertake per-cutaneous nephrostomy pre-operatively for those individuals that have significant pus within their kidneys to help reduce the bulk of the kidney and to drain pus containing the offending micro-organism in order to minimize the development of bacteraemia and sepsis during the nephrectomy as well as to make the operation technically less difficult.

Gasmi et al. [8] reported a 2-year-old boy who had presented with a 2-weeks history of fever and right loin pain. His clinical examination showed a mass in his right lumbar region. His white blood cell count was 12.800 per $\mathrm{mm}^{3}$ and his $\mathrm{C}$ reactive protein level was raised at $50 \mathrm{mg}$ per $\mathrm{l}$. His urine culture was negative. He had ultrasound scan and computed tomography (CT) scan of his abdomen and pelvis which showed a focal multilocular cystic mass within the lower pole of his right kidney that measured $8 \mathrm{~cm}$, with peripheral enhancement and perirenal involvement. During surgical exploration of the mass, a huge abscess which had involved the lower pole of the right kidney with dense adhesions to the adjacent structures was observed. Excision of the collection together with local drainage of the abscess were undertaken. Pathology examination of the biopsy specimens taken revealed features that confirmed the diagnosis of xanthogranulomatous pyelonephritis. The intra-operative culture of the pus that was obtained grew Escherichia coli. Successful treatment of the patient was achieved with utilization of adjunctive appropriate antibiotic treatment. He had remained well over a follow-up period of 2 years. Gasmi et al. [8] made the ensuing conclusions:

- XGP should be taken into consideration with regard to the differential diagnosis of a renal mass.

- A first-line conservative treatment must be strongly recommended with regard to paediatric focal cases of XGP.

To the conclusions of Gasmi et al. [8] some people would add with regard to selected patients who have focal abscess / XGP related to one pole of the kidney if there is availability of a well-trained interventional radiologist then a first line approach option that could be considered would be radiology imaging guided aspiration/drainage of the abscess and this should be combined with biopsy of the diseased kidney tissue and leaving in situ a percutaneous nephrostomy as well as a peri-renal drain to be undertaken under general anaesthesia which should be adjointly combined with antibiotics treatment in order to avoid open surgical drainage but if this option fails one can then move on to the open surgical drainage and biopsy approach.

Chandrakunnel et al. [15] reported a 68-year-old woman who had manifested with pyrexia of unknown origin. She had computed tomography (CT) scan of abdomen and pelvis which showed an irregularly enlarged kidney. The results of her blood tests did show a highly elevated erythrocyte sedimentation rate of greater than $100 \mathrm{~mm}$ per hour, an elevated serum ferritin level, as well as chronic thrombocytosis, which had favoured a diagnosis of renal cell carcinoma. Other differential diagnoses that were considered included: malakoplakia of the kidney and tuberculosis of the kidney. It was noted that non-visible haematuria could be present in any of the aforementioned differential diagnoses but the patient did not have non-visible haematuria. The features of the abdominal CT scan she had had been suggestive of Xanthogranulomatous pyelonephritis. She underwent nephrectomy to remove the irregularly enlarged kidney. The pathology examination features of the kidney were consistent with the diagnosis of xanthogranulomatous pyelonephritis without any renal cell carcinoma.

Chow et al. [16] reported a 43-year-old lady of Russian ethnicity who had presented with about 24 hours history of sub-xiphoid pleuritic chest pain which had radiated to her left shoulder tip and her left flank. She had undergone in the past conservative treatment for nephrolithiasis. Her symptoms had included intermittent fevers, night sweats, a weight loss that amounted to 7 kilograms 
over the preceding 6 weeks. Her general and systematic examinations were unremarkable apart from temperature of $36.2^{\circ} \mathrm{C}$, blood pressure of 138/96 mm Hg in the sitting position, heart rate of regular 130 beats per minute and a respiratory rate of 22 breaths per minute. Her oxygen saturation based upon pulse oximetry was $97 \%$. The results of her initial investigations included: White blood cell count $12.9 \times 10^{9}$ with predominantly neutrophils, elevated C-reactive protein of $17.9 \mathrm{mg} / \mathrm{dL}$, and microcytic anaemia of recent onset with a haemoglobin of $88 \mathrm{~g} / \mathrm{L}$. A study of her previous laboratory results had shown that the results of her haemoglobin was previously normal at $130 \mathrm{~g} / \mathrm{L} 2$ years earlier, but her thrombocytosis (with platelet levels between 400 and $600 \times 109$ had been present for a while. Her serum troponin and ECG studies were normal but she had CT scan of thorax which revealed a small left-sided pleural effusion and a loculated effusion which measured $10.3 \mathrm{~cm} \times 3.4 \mathrm{~cm}$ $\mathrm{x} 5.6 \mathrm{~cm}$ in her subcapsular region encompassing her spleen. The results of her blood and urine culture as well as autoimmune markers were normal. She had CT scan of abdomen and pelvis which showed a calculus within her left kidney with encompassing inflammatory soft tissue changes that had included dilated renal calyces overlying a paradoxically contracted renal pelvis (the classic "bear's paw sign" of XGP. The inflammatory changes had extended to the sub-capsular effusion, the inferior tip of her spleen parenchyma, as well as it had communicated with her left hemidiaphragm (see figure 1 ). A diagnosis of XGP was made. She was commenced initially on intravenous piperacillin-tazobactam for 7 days pre-operatively following which she underwent successful laparoscopic nephrectomy that was followed by 7 days course of intravenous piperacillin-tazobactam. Her urine cultures, blood cultures, as well as cultures of specimens of her kidney did not reveal any organism. She was discharged home on a 7 day course of cefixime $200 \mathrm{mg}$ orally daily. At nearly her 8-month post-operative follow-up she was asymptomatic and well.
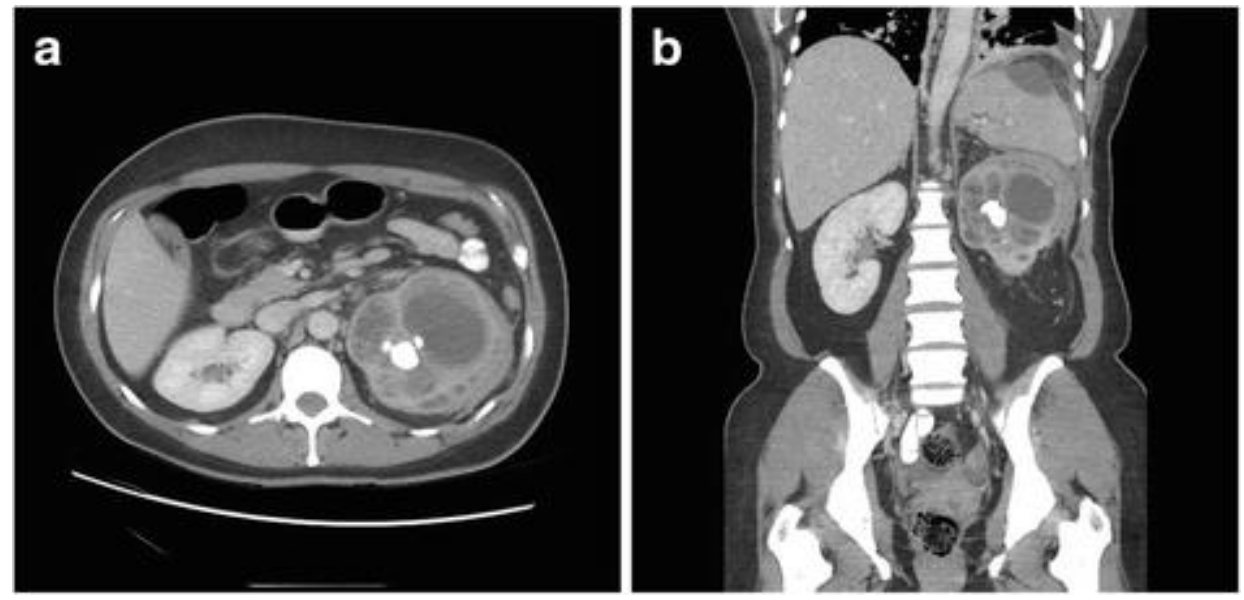

Figure 1: Computed tomography of the abdomen and pelvis demonstrating xanthogranulomatous pyelonephritis of the left kidney. (a) axial section at the level of the renal calyces demonstrating markedly abnormal appearance of the left kidney. The renal pelvis is contracted around a staghorn calculus with surrounding distension and ballooning in the upper pole calyces, with surrounding soft tissue stranding and enlarged perinephric and retroperitoneal lymph nodes which are presumed to be reactive. (b) Coronal section of the abdomen and pelvis showing aforementioned changes in the left kidney with superior extension into the spleen parenchyma. Tracking of the inflammatory perinephric soft tissue along the posterior aspect of the spleen (not shown in this view) connects with a large hypodense collection under the splenic capsule, which also appears to communicate across left hemidiaphragm with resulting left-sided pleural effusion. Reproduced from: [16] Chow J, Kabani R, Lithgow K, Sarna M A. Xanthogranulomatous pyelonephritis presenting as acute pleuritic chest pain: a case report. Journal of 
Medical Case Reports. 2017; 11: $101 \quad$ DOI: 10.1186/s13256-017-1277-4 https://jmedicalcasereports.biomedcentral.com/articles/10.1186/s13256-017-1277-4\#citeas Accessed 2019 Dec 03 under copyright Open Access This article is distributed under the terms of the Creative Commons Attribution 4.0 International License (http://creativecommons.org/licenses/by/4.0/), which permits unrestricted use, distribution, and reproduction in any medium, provided you give appropriate credit to the original author(s) and the source, provide a link to the Creative Commons license, and indicate if changes were made. The Creative Commons Public Domain Dedication Waiver (http://creativecommons.org/publicdomain/zero/1.0/) applies to the data made available in this article, unless otherwise stated.

Macroscopic examination of the specimen showed inflammation that included inflammatory marked abnormalities that included dilated renal lymphoplasmatic infiltrates that had layered calyces, greenish/tan and pink purulent material, as well as many intraluminal calculi. No organisms were cultured from the specimen. Parts of the capsule of the kidney were congested and there were four surrounding enlarged lymph nodes. Microscopy examination of the specimen (see figure 2) showed evidence of chronic sheets of histiocytes. Michaelis-Gutmann bodies that are pathognomonic for malakoplakia were also visualised. Based upon the aforementioned findings a diagnosis of Xanthogranulomatous pyelonephritis in association with malakoplakia co-existence was made.
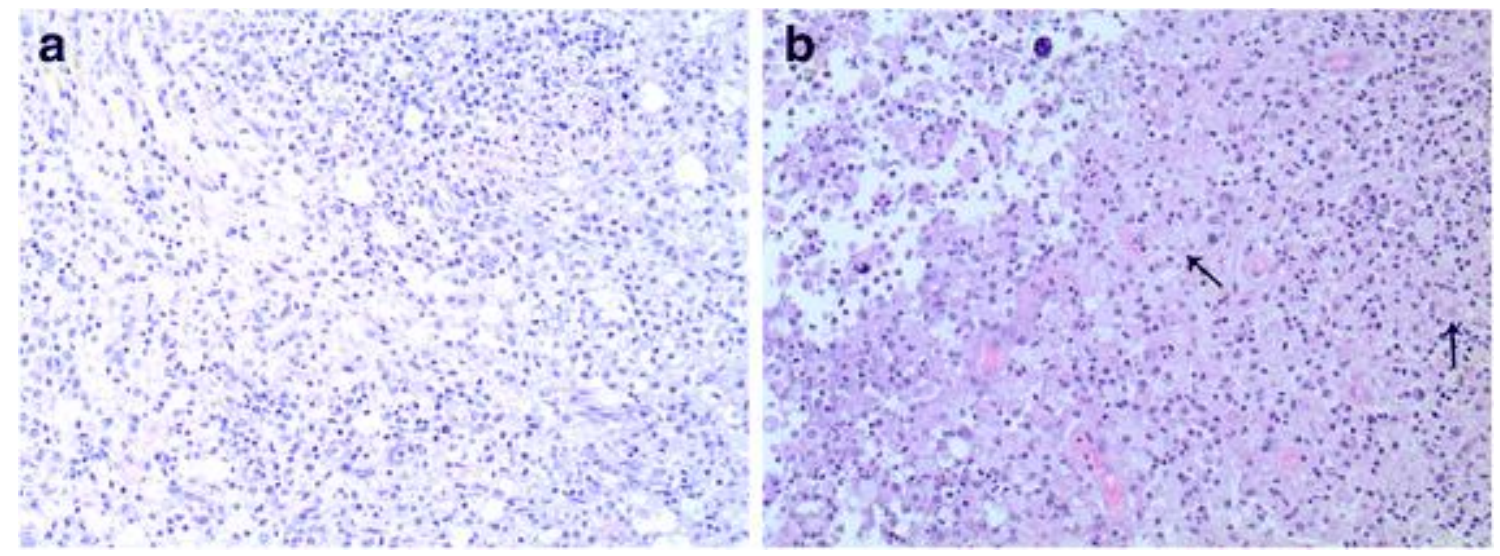

Figure 2: Xanthogranulomatous pyelonephritis and coexisting malakoplakia of the left kidney. Histopathological examination of the surgical specimen with haematoxylin and eosin staining reveals microscopic features of chronic inflammation. a Heavy lympholasmatic infiltration. b Inflammatory infiltrates with layered sheets of histiocytes. Michaelis-Gutmann bodies pathognomonic for malakoplakia (granulomatous inflammation of the genitourinary tract) are indicated by arrows. Reproduced from: [16] Chow J, Kabani R, Lithgow K, Sarna M A. Xanthogranulomatous pyelonephritis presenting as acute pleuritic chest pain: a case report. Journal of Medical Case $\quad$ Reports. 2017; $\quad 11: \quad 101 \quad$ DOI: $10.1186 / s 13256-017-1277-4$ https://jmedicalcasereports.biomedcentral.com/articles/10.1186/s13256-017-1277-4\#citeas Accessed 2019 Dec 03 under copyright Open Access This article is distributed under the terms of the Creative Commons Attribution 4.0 International License (http://creativecommons.org/licenses/by/4.0/), which permits unrestricted use, distribution, and reproduction in any medium, provided you give appropriate credit to the original author(s) and the source, provide a link to the Creative Commons license, and indicate if changes were made. The Creative Commons Public Domain Dedication Waiver (http://creativecommons.org/publicdomain/zero/1.0/) applies to the data made available in this article, unless otherwise stated. 
Enshaei et al. [17] reported a 58-year-old woman who had presented with severe pulmonary infection associated with morbid obesity and insulin dependent diabetes mellitus over the preceding 17 years as well as with a history of hypertension and hyperlipidaemia and cholecystectomy. She had recently lost 25 kilograms weight with utilization of Liraglutide injections. She was asymptomatic otherwise. She has had an elevated ESR of unknown cause over a long period of time. Her urinalysis revealed non visible haematuria. She had ultrasound scan of abdomen and pelvis which showed a large rounded hypoechoic solid looking mass within the lower pole of her right kidney that was adjudged to be virtually not distinguishable from a kidney malignancy. The ultrasound scan also showed two small lesions within her liver which were considered to be haemangiomas (see figure 3). She had contrast-enhanced CT scan of her abdomen and pelvis which showed a $10 \mathrm{~cm}$ x $8 \mathrm{~cm}$ heterogeneous soft tissue mass within the lower pole of her right kidney. The mass did have faint contrast-enhancement as well as adjacent fat stranding and para-renal facial thickening. The CT scan also demonstrated bear's paw sign as a result of dilatation of the renal calyces (see figure
4). Based upon the CT scan image findings the differential diagnoses that were considered included: probable complex cystic renal mass, renal malignancy, and cystic degeneration of the kidney. She also had chest x-ray which showed mild pleural effusion as well as a soft tissue density pleural based lesion within the right hemithorax. She had a contrast-CT scan of thorax which showed bilateral smaller $2 \mathrm{~cm}$, irregular bordered nodules within both lung fields. The CT scan also demonstrated a $3.5 \mathrm{~cm}$ x $2.5 \mathrm{~cm}$ cavitating lesion within the right upper lobe, a wedge-shaped consolidation within the right lower lobe, right pleural effusion, and right hilar lymph node enlargement. These intrathoracic lesions were suspected to be probably thoracic metastases. The results of her urinalysis, urine culture, haematology and biochemistry blood tests were generally normal except an elevated ESR of 99 in 1 hour, low serum sodium of 130 (normal range 136 - 145), normocytic anaemia with a haemoglobin of 10.3 (normal range 12 17), a slightly raised white blood cell count of 10.1 (normal range 4-10), The levels of tumour markers including CEA, CA19-9, CA125, and CA15-3 were normal.
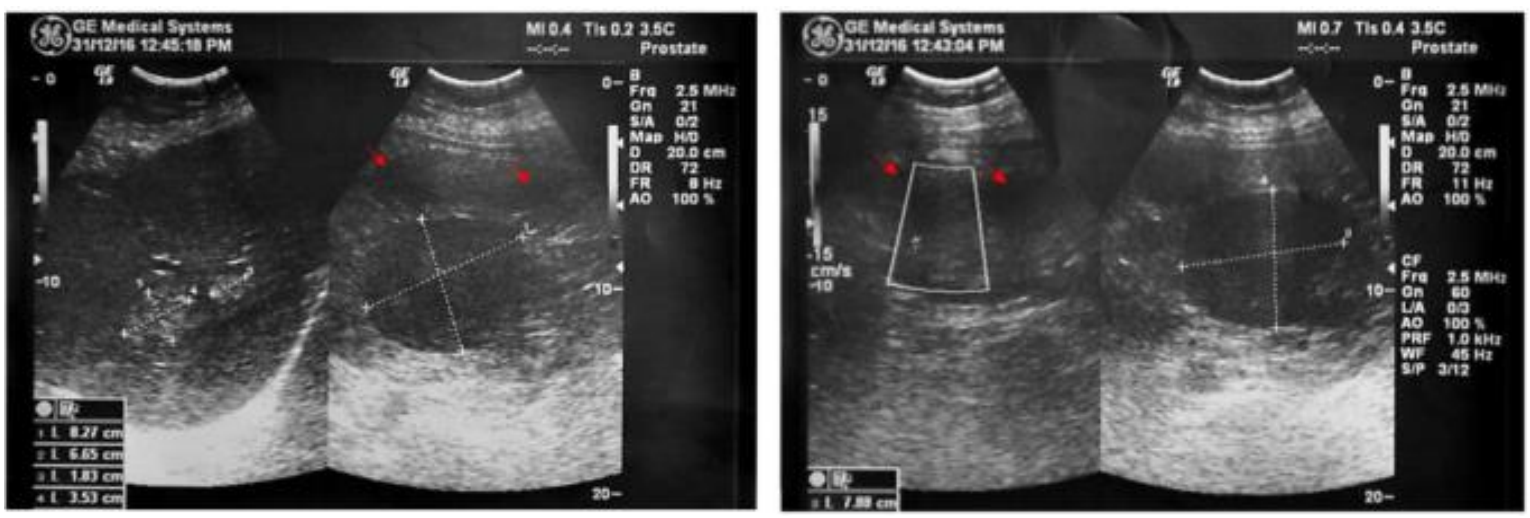

Figure 3: The right kidney masses probably are liver hematomas (red arrows). Reproduced from: [17] Enshaei A, Boora A A, Taheri D, Changizi Z, Bahmani N. Focal Xanthogranulomatous Pyelonephritis with Pulmonary Lesions on the Background of Type Two Diabetes Mellitus. Case Reports in Radiology Volume 2018; Article ID 1698285, 5 
pages https://doi.org/10.1155/2018/1698286 https://www.hindawi.com/journals/crira/2018/1698286/ Accessed 2019 Dec 03 under copyright (C) 2018 Ahmad Enshaei et al. This is an open access article distributed under the Creative Commons Attribution License, which permits unrestricted use, distribution, and reproduction in any medium, provided the original work is properly cited.
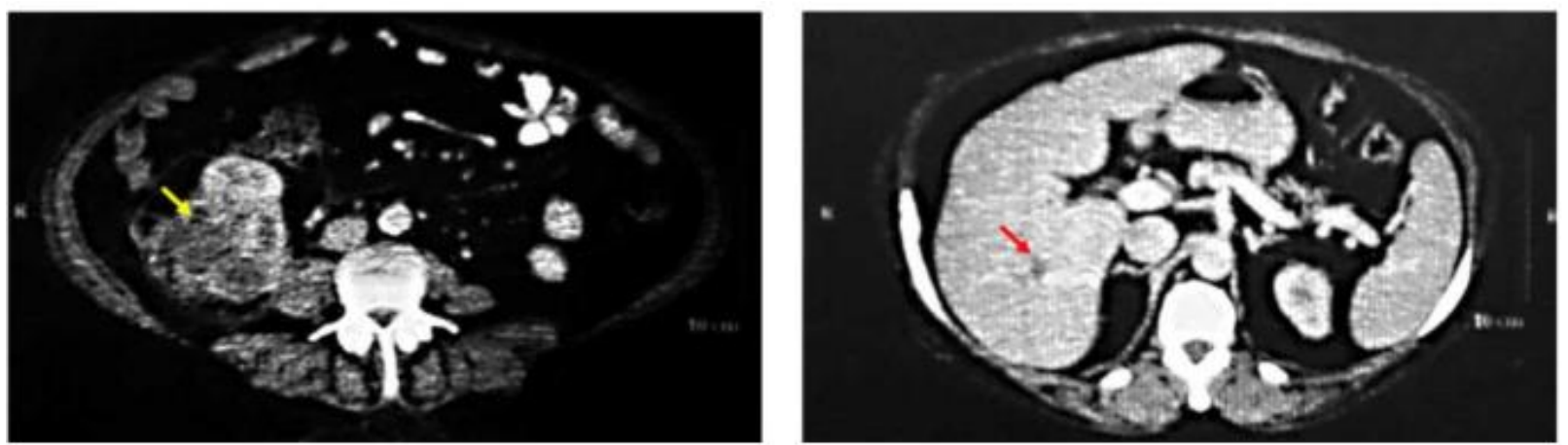

Figure 4: CT of abdomen. Yellow arrow: mass attached to the right kidney (yellow arrow) on CT scan with bear paw sign. Red arrows: probably liver haemangiomas. Reproduced from: [17] Enshaei A, Boora A A, Taheri D, Changizi Z, Bahmani N. Focal Xanthogranulomatous Pyelonephritis with Pulmonary Lesions on the Background of Type Two Diabetes Mellitus. Case Reports in Radiology Volume 2018; Article ID 1698285, 5 pages https://doi.org/10.1155/2018/1698286 https://www.hindawi.com/journals/crira/2018/1698286/ Accessed 2019 Dec 03 under copyright (C) 2018 Ahmad Enshaei et al. This is an open access article distributed under the Creative Commons Attribution License, which permits unrestricted use, distribution, and reproduction in any medium, provided the original work is properly cited.
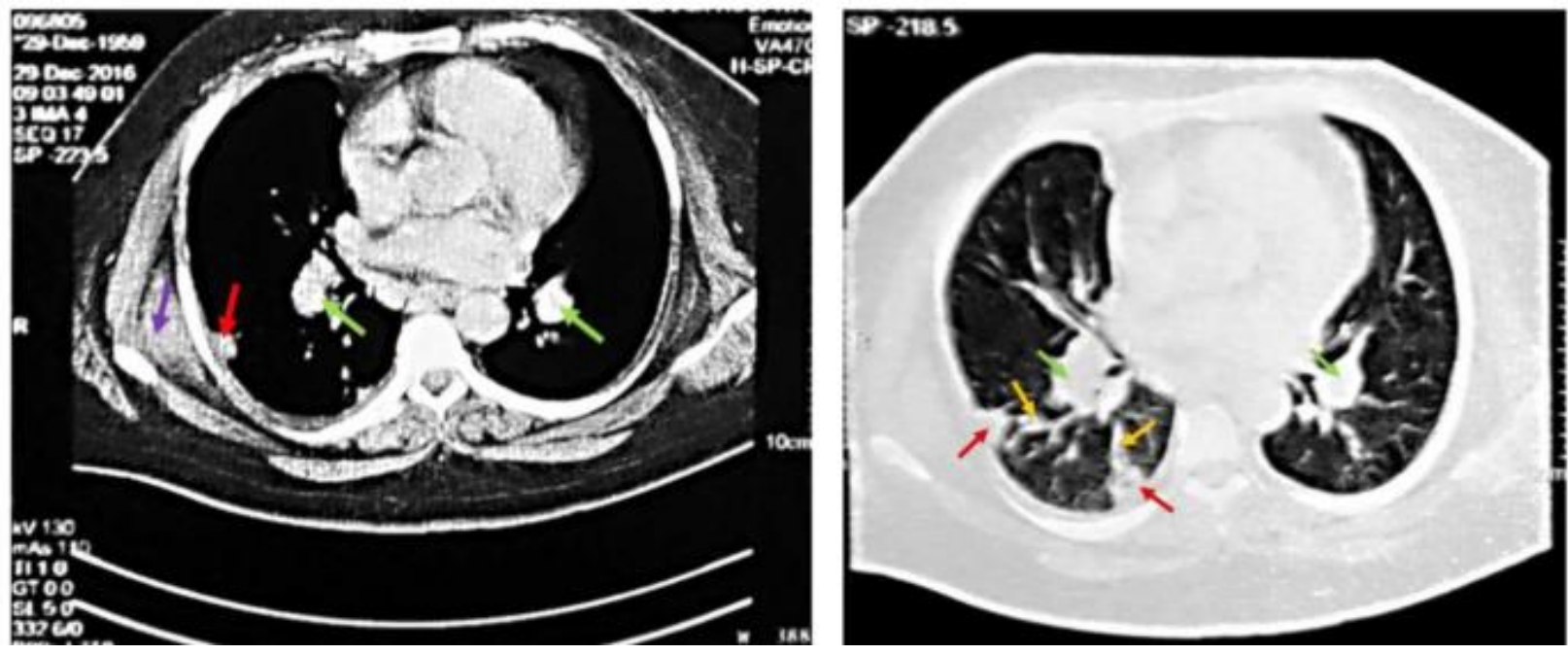

Figure 5: CT of Chest. Lung lesions. Hilar adenopathies (green arrows), probable septic embolization (red arrows), feeding vessels (yellow arrow), serratus anterior muscle purple arrow. Reproduced from: [17] Enshaei A, Boora A A, Taheri D, Changizi Z, Bahmani N. Focal Xanthogranulomatous Pyelonephritis with Pulmonary Lesions on the Background of Type Two Diabetes Mellitus. Case Reports in Radiology Volume 2018; Article ID 1698285, 5 pages https://doi.org/10.1155/2018/1698286 https://www.hindawi.com/journals/crira/2018/1698286/ Accessed 2019 Dec 03 under copyright (C) 2018 Ahmad Enshaei et al. This is an open access article distributed under the Creative Commons Attribution License, which permits unrestricted use, distribution, and reproduction in any medium, provided the original work is properly cited. 


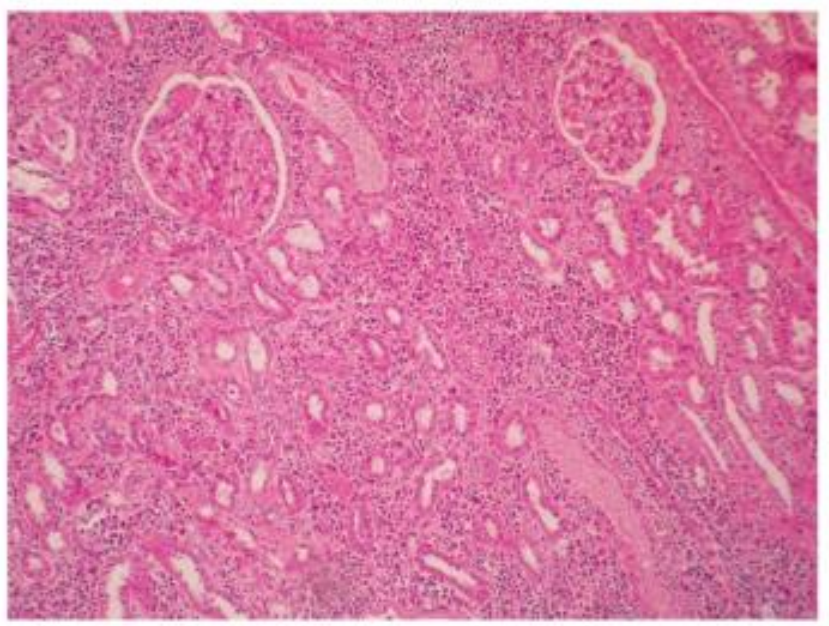

Figure 6: There is marked mixed inflammation in renal parenchyma in the background of diabetic nephropathy (nodular sclerosis). H\&E 100x. Reproduced from: [17] Enshaei A, Boora A A, Taheri D, Changizi Z, Bahmani N. Focal Xanthogranulomatous Pyelonephritis with Pulmonary Lesions on the Background of Type Two Diabetes Mellitus. Case Reports in Radiology Volume 2018; Article ID 1698285, 5 pages https://doi.org/10.1155/2018/1698286 https://www.hindawi.com/journals/crira/2018/1698286/ Accessed 2019 Dec 03 under copyright (C) 2018 Ahmad Enshaei et al. This is an open access article distributed under the Creative Commons Attribution License, which permits unrestricted use, distribution, and reproduction in any medium, provided the original work is properly cited.

Based upon the radiology imaging features of the lesion (figures 4 and 5) a suggestion of kidney tumour with pulmonary metastasis was made. She underwent right nephrectomy following which she recovered well and became asymptomatic without fever and her ESR dropped to $66 \mathrm{~mm} / \mathrm{hr}$ and her white blood cell count reduced to 7.1 which were within the normal range. Microscopy examination of the kidney showed focal replacement of renal parenchyma by severe mixed inflammatory cell infiltrations including lymphoplasma cells, neutrophils, and foamy histiocytes infiltration as well as fibrosis with extension into the perirenal soft tissue. Diabetic nephropathy with nodular sclerosis and arteriolar hyalinosis was visualised within the background (see figure 6). A diagnosis of Xanthogranulomatous pyelonephritis was made. At about her 3-month follow-up, she had a CT scan of the thorax which demonstrated that her pulmonary nodules had resolved spontaneously. Lessons learnt this case report include the fact that Xanthogranulomathous pyelonephritis could be a focal lesion at times and that Xanthogranulomatous

pyelonephritis does mimic a malignancy of the kidney.

Ramos et al. [18] stated that the diagnosis of pyelonephritis tends to be easy to establish with regard to the majority of cases; however, there are unusual presentations of pyelonephritis that make its diagnosis difficult to establish. Ramos et al. [18] reported a case of Xanthogranulomtous pyelonephritis as follows:

A 48-year old lady manifested with a 2-weeks history of lumbar pain which was associated with asthenia, visible haematuria, and loss of 15 kilograms weight over a period of 3 months. Her comorbidities included diabetes mellitus that was treated with metformin, hypertension which was treated with losartan, as well as renal lithiasis. Her clinical examination revealed pallor, normal blood pressure of $120 / 70 \mathrm{~mm} \mathrm{Hg}$, tachycardia with a pulse rate of 120 beats per minute, normal respiratory rate and a temperature of $36.5^{\circ}$ centigrade. She was noted to have abdominal distension and a mass was palpable within her left hypochondrium and left flank. The results of her routine haematology and 
biochemistry blood tests revealed Haematocrit of $20 \%$, Haemoglobin of 6.3 grams per decilitre, white blood cell count of 21,700 per cubic millimetre, with $77 \%$ neutrophils, platelets 559,000 per cubic millimetre, creatinine 1.4 milligrams per decilitre, and urea 46 milligrams per decilitre. Her urinalysis showed PH of 6, proteinuria of 2+, leucocyturia of $4+$, haematuria of $4+$, and bacteriuria. Her urine culture grew Escherichia coli. She was commenced on levofloxacin. She had ultrasound scan of her abdomen which revealed a staghorn calculus in her left kidney with signs of Xanthogranulomatous pyelonephritis. She had computed tomography (CT) scan which revealed characteristics replacement of the kidney tissue by many rounded, low-density areas, which were encompassed by an enhanced rim of contrast medium. The images were interpreted as corresponding to dilated calyces that had been lined with necrotic xanthomatous tissue which had extended into the parenchyma of the kidney (see figure 7). She underwent insertion of left sided percutaneous nephrostomy with drainage of 2 litres of purulent secretion. She was continued on antibiotics and she steadily improved symptomatically. Ramos et al. [18] stated the ensuing:

- It has been documented that xanthogranulomatous pyelonephritis and emphysematous pyelonephritis are two uncommon, atypical, and severe forms of renal parenchymal infection [19] [20] [21]

- Emphysematous pyelonephritis was first described by Kelly and McCullum in 1898 [22], and xanthogranulomatous pyelonephritis was described by Schlagenhaufer in 1916 which was termed staphylocomycosis in view of its similarity to actinomyces and the presence of staphylococcus. In 1935, staphylocomycosis was re-named xanthogranulomatous pyelonephritis by Oberling [23]; [24].

- Xanthogranulomatous pyelonephritis tends to be typified by a chronic inflammatory process that leads to destruction of the parenchyma of the kidney with its subsequent replacement by a granulomatous tissue that contain mononuclear macrophages and lipids that are referred to as Xanthomam cells [25]; [26]. This clinical entity of xanthomatous pyelonephritis does represent $1 \%$ of all kidney infections. Xanthogranulomatous pyelonephritis is four times more frequently encountered in women who are in their $50^{\text {th }}$ and $60^{\text {th }}$ years of their lives $\left(^{\text {th }}\right.$ and $6^{\text {th }}$ decades); nevertheless, it has been stated that xanthogranulomatous pyelonephritis can occur at any age [27]. With regard to majority of cases of xanthogranulomatous pyelonephritis, the disease tends to be unilateral, and the right kidney tends to be more often involved. Cases of bilateral xanthogranulomatous pyelonephritis have been considered to be fatal diseases [25]; [27]. It has been documented that patients who are afflicted by xanthomatous pyelonephritis tend to have diabetes and immunosuppression [20].

- Xanthogranulomatous pyelonephritis tends to be associated with kidney stones in $75 \%$ to $86 \%$ of cases. The commonest associated infectious agents have been proteus and Escherichia coli, which have been documented to be involved with regard to $30 \%$ to $40 \%$ of cases [25]. It has been iterated that nearly $10 \%$ of patients who have xanthogranulomatous pyelonephritis have negative cultures [19].

- It has been iterated that xanthogranulomatous pyelonephritis frequently tends to be misdiagnosed as renal cell carcinoma in view of its clinical manifestation and radiology imaging appearance [29] Evidence of chronic urinary tract infection as well as computed tomography (CT) scan images usually tend to make it easier to differentiate these disorders. Even though, on rare occasions, 
the two disorders could occur together contemporaneously. Xanthogranulomatous pyelonephritis should also be differentiated histologically from two other inflammatory conditions that include: malakoplakia of renal parenchyma, and megalocytic interstitial nephritis [30].

- Computed tomography (CT) scan has presently become the best tool to diagnose infections of xanthogranulomatous pyelonephritis and emphysematous pyelonephritis and it has been stated that it is important to establish the presence as well as extension of extra-renal involvement in these infections [21]; [25]; [26]; [31]; [32]. The most common findings upon the CT scans of individuals who have xanthogranulomatous pyelonephritis include: calculi, hydronephrosis, kidney enlargement, as well as hypo-dense areas together with destruction of renal parenchyma [21]; [31]; [33]. Other diagnostic methods have been utilized in the investigation of xanthogranulomatous pyelonephritis and emphysematous pyelonephritis including: micturition cystourethrogram, ultrasound scan, and renal scintigraphy [21]; [27]; [31].

- With regard to treatment, the gold standard treatment for xanthogranulomatous pyelonephritis and emphysematous pyelonephritis does entail nephrectomy which also tends to be total nephrectomy with regard to the majority of cases and during the operation it would be important to remove circum-adjacent inflammatory tissues. With regard to rare cases of xanthogranulomatous pyelonephritis, partial nephrectomy could be successfully undertaken [19]; [21]; [23]; [25]; [31]; [32]; [33]. Insertion of per-cutaneous nephrostomy preceding the nephrectomy could be considered a method that would facilitate the surgical operation, due to the fact that it would enable a reduction in the size of the mass of the kidney which would favour access to the kidney during the undertaking of the nephrectomy [19]; [22]; [31].

- It has been iterated that utilizations of antibiotics alone tend not to be effective with regard to the treatment of Xanthogranulomatous pyelonephritis and emphysematous pyelonephritis; nevertheless, antibiotics should be commenced preceding the surgical procedure in order to control the infectious process and in order to avoid the development of sepsis.

Considering that magnetic resonance imaging (MRI) scans are available in most countries, it would be added that MRI scans could also form a very useful and excellent radiology imaging option to investigate patients who have xanthogranulomatous pyelonephritis. 


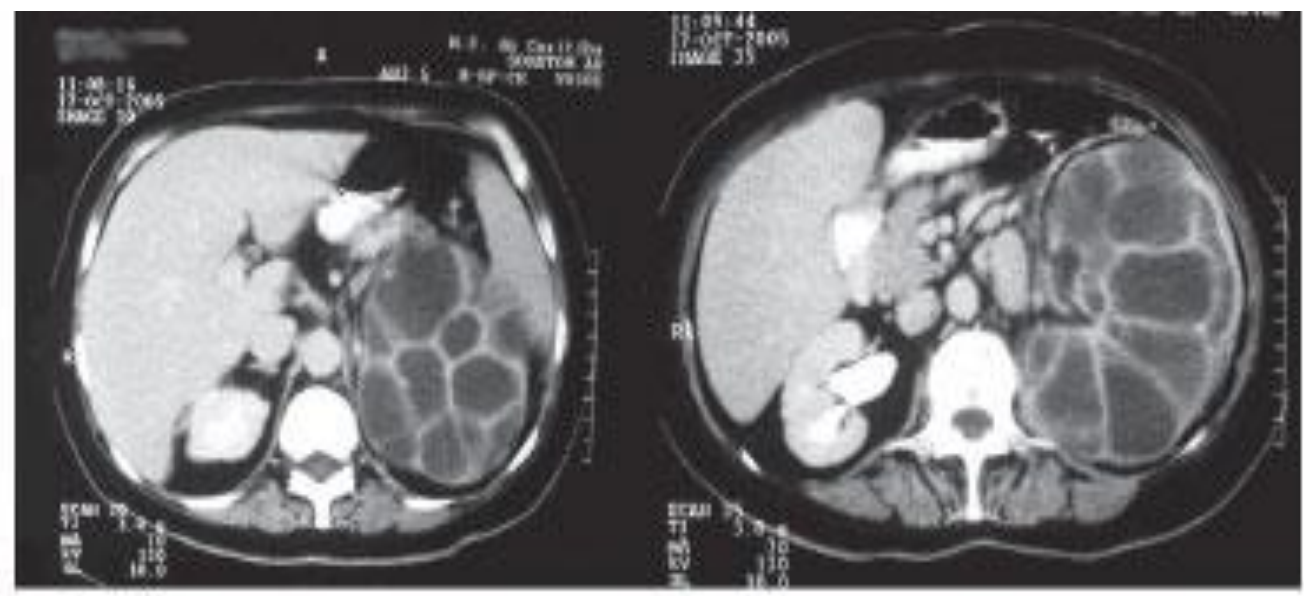

Figure 7: CT scan of xanthogranulomatous pyelonephritis. There is diffuse enlargement of the left kidney and the renal tissue is replaced by multiple low-attenuated masses. The contralateral kidney is normal. Reproduced from: [18] Ramos L D, Lima M D M, de Carvalho M, da Silver Junior G B, Daher E D F. Emphyematous and granulomatous pyelonephritis: rare diagnosis. Brazilian Journal of Infectious Diseases. 2010 Jul-Aug; 14(4): http://dx.doi.org/10.1590/S1413-86702010000400011

http://www.scielo.br/scielo.php?script=sci arttext\&pid=S1413-86702010000400011 Accessed 2019 Dec 04 under The Creative Commons Attribution License (CC BY-Nc-ND), All the contents of this journal, except where otherwise noted, is licensed under a Creative Commons Attribution License.

Mardi et al. [9] reported two cases of the co-existence of keratinizing squamous cell carcinoma with xanthogranulomatous pyelonephritis in the same kidney as follows:

\section{Case 1}

A 65-years-old man had manifested with fever, and pain in his left loin of 2-months duration. He had a past history of urolithiasis many years earlier. His clinical examination revealed tenderness over his left costovertebral angle as well as a palpable mass within the left upper quadrant of his abdomen. The results of his routine biochemistry blood tests were within normal range. He had ultrasound scan of his abdomen and renal tract which showed evidence of left sided hydronephrosis with multiple calculi (see figure 8). He underwent left nephrectomy. Macroscopic examination of the nephrectomy specimen showed upon cut section, an enlarged kidney which contained lobules of yellowish areas with focal grey-white areas as well as dilated pelvicalyceal system that had been lined by metaplastic squamous epithelium that showed malignant transformation with nests of malignant squamous epithelium forming pearls that had invaded the underlying stroma and encompassing renal parenchyma which showed features of xanthogranulomatous pyelonephritis.

\section{Case 2}

A 60-year-old woman who had a past history of urolithiasis many years ago had presented with a history of intermittent right loin pain. Her clinical examination demonstrated tenderness in her right costovertebral angle as well as a palpable mass within the right upper quadrant of her abdomen. The results of her routine haematology and biochemistry blood tests were within normal range. She had contrast enhanced computed tomography scan (CECT) of her abdomen and pelvis which demonstrated a right sided hydronephrosis with many small stones in a dilated pelvicalyceal system. She did undergo right nephrectomy. Macroscopic examination of the nephrectomy specimen showed an enlarged kidney which upon cut section demonstrated dilated pelvicalyceal system that contained many white coloured stones. There was a growth which was irregular grey-white that had arisen from the renal pelvis that measured $5 \mathrm{~cm} \mathrm{x} 3$ 
$\mathrm{cm}$. The encompassing renal residual parenchyma demonstrated yellow looking areas. Microscopy examination of the specimen showed well differentiated squamous cell carcinoma with pearl formation invading adjacent parenchyma of the kidney (see figure 9). Areas of the renal pelvis located adjacent to the growth did reveal squamous metaplasia. The perinephric fat did not contain any tumour. The surrounding parenchyma of the kidney did demonstrate characteristic features of xanthogranulomatous pyelonephritis with sheets of foamy macrophages, many foreign body giant cells, lymphocytes, plasma cells, occasional neutrophils, cholesterol clefts, as well as fibrosis within the interstitial tissue (see figure 10). Based upon the pathology examination features of the specimen, a diagnosis of well differentiated squamous cell carcinoma with xanthogranulomatous pyelonephritis was established. Mardi et al [9] iterated the following:

- Xanthogranulomatous pyelonephritis is an uncommon form of chronic pyelonephritis that is commonly associated with lithiasis and on rare occasions does emanate into keratinising squamous metaplasia [34].

- The manifestations of xanthogranulomatous pyelonephritis closely simulate those of neoplasm of the kidney which had lead to misdiagnosis as malignancy that often did result in the undertaking of nephrectomy. As metaplasia has been known to occur in association with calculi, its presence in association with xanthogranulomatous pyelonephritis is not surprising. Nevertheless, only isolated incidence of such lesions has been documented, where metaplasia had already emanated into squamous cell carcinoma. [35]

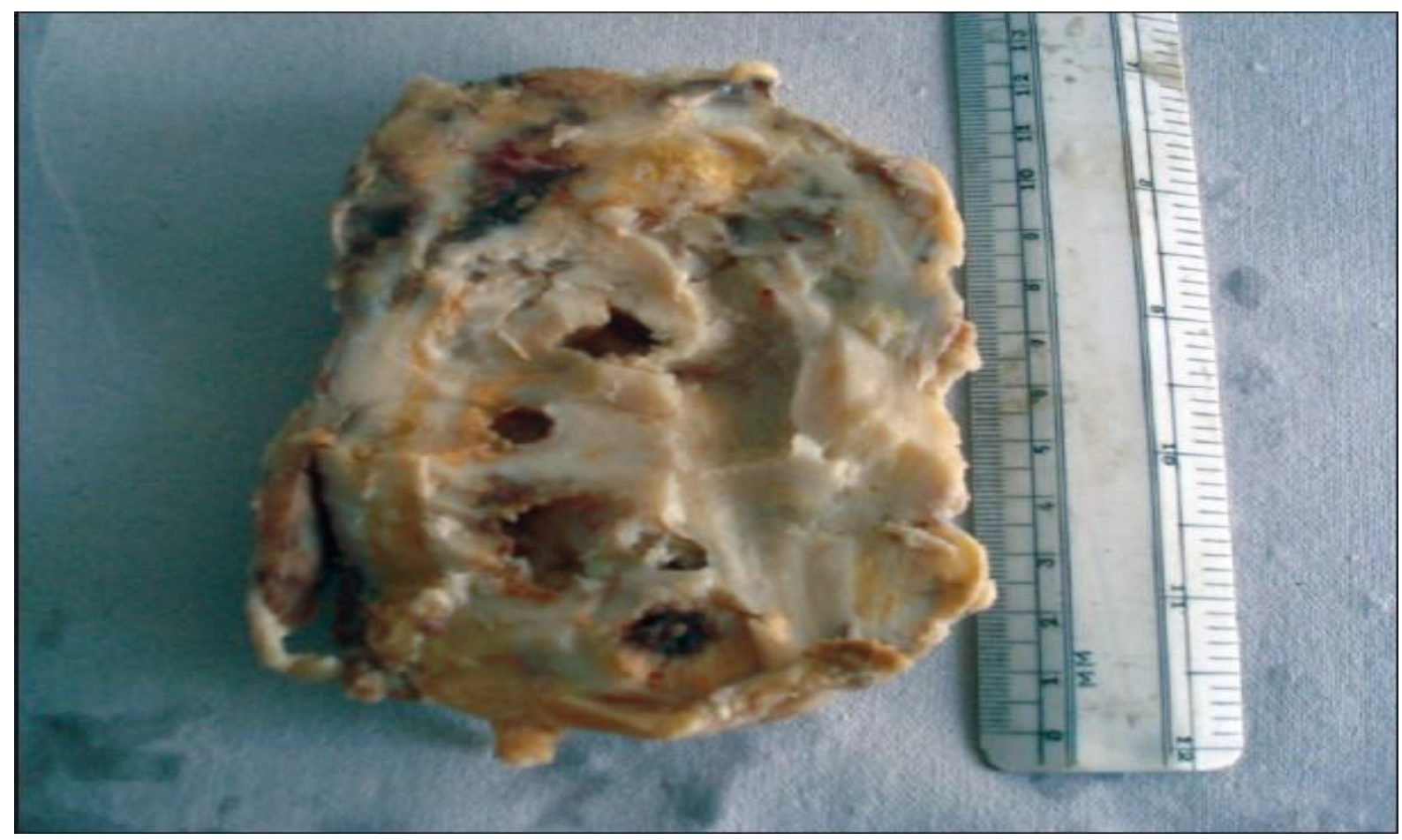

Figure 8: Cut section of the enlarged kidney showing predominantly yellowish areas with focal grey white and cystic areas. Reproduced from: [9] Mardi K, Kaushal V, Sharma V. Rare coexistence of keratinising squamous cell carcinoma with xanthogranulomatous pyelonephritis in the same kidney: Report of two cases. Journal of Cancer 
Anthony Kodzo-Grey Venyo; Xanthogranulomatous Pyelonephritis A Review and Update of the Literature www.irmhs.com

Research and Therapeutics. 2010; 6(3): $339 \quad-\quad 341 \quad$ DOI: $10.4103 / 0973-1482.73351$ http://www.cancerjournal.net/article.asp?issn=0973-

1482; year $=2010 ;$ volume $=6$;issue $=3 ;$ spage $=339$; epage $=341$; aulast $=$ Mardi \# Accessed 2019 Dec04] under copyright (C) 2010, Wolters Kluwer Medknow Publications This article is available under the terms of the Creative Commons Attribution-NonCommercial-ShareAlike License (CC BY-NC-SA), which permits non-commercial use, distribution and reproduction in any medium, provided the original work is properly cited.

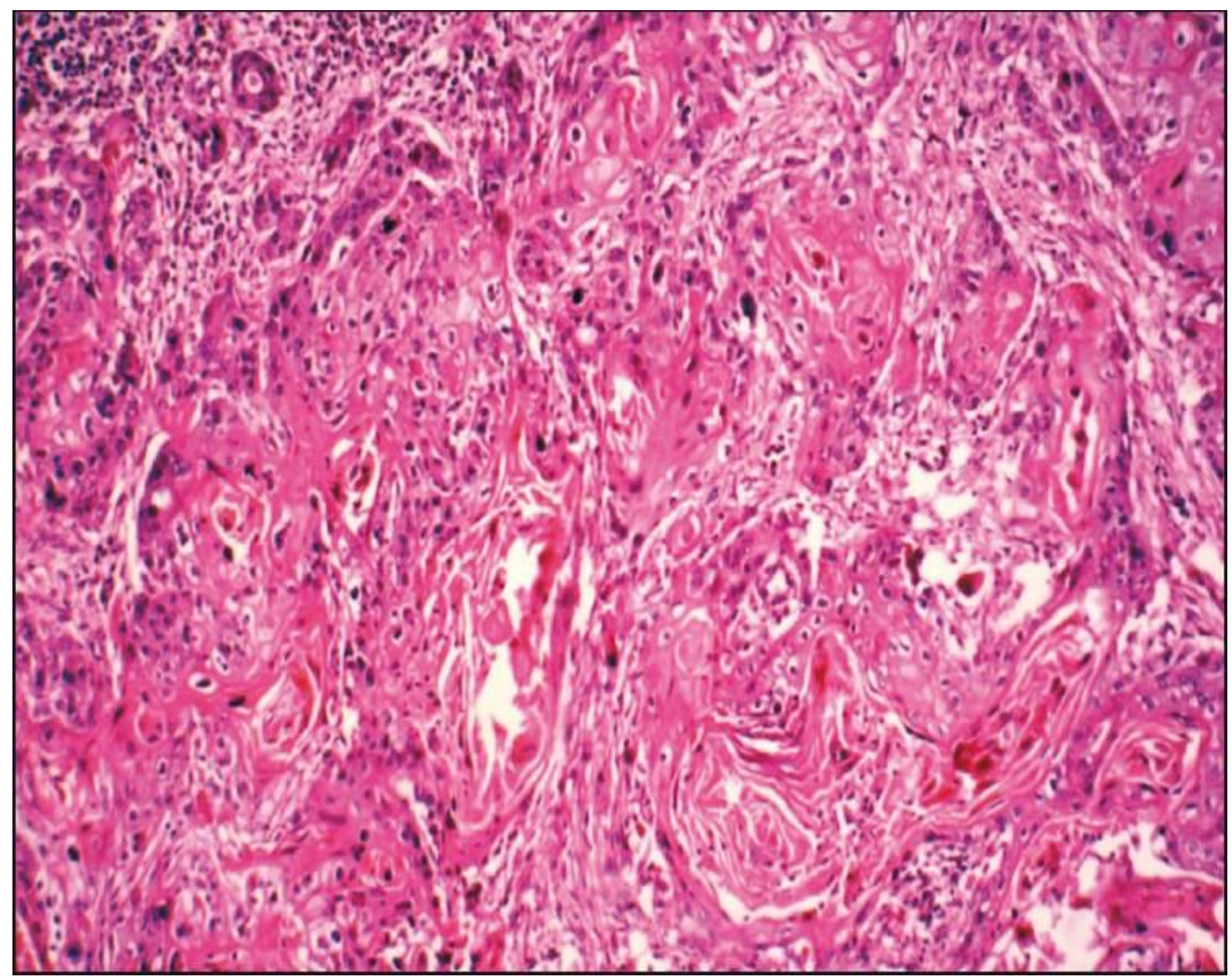

Figure 9: Photomicrograph showing areas of well differentiated squamous cell carcinoma (H and E, $40 \mathrm{x}$ ). Reproduced from: [9] Mardi K, Kaushal V, Sharma V. Rare coexistence of keratinising squamous cell carcinoma with xanthogranulomatous pyelonephritis in the same kidney: Report of two cases. Journal of Cancer Research and $\begin{array}{llllll}\text { Therapeutics. } & 2010 ; & 6 & \end{array}$ http://www.cancerjournal.net/article.asp?issn=09731482; year=2010; volume=6;issue=3; Spage=339; epage=341; aulast=Mardi\# Accessed 2019 Dec04] under copyright (C) 2010, Wolters Kluwer Medknow Publications This article is available under the terms of the Creative Commons Attribution-NonCommercial-ShareAlike License (CC BY-NC-SA), which permits non-commercial use, distribution and reproduction in any medium, provided the original work is properly cited. 


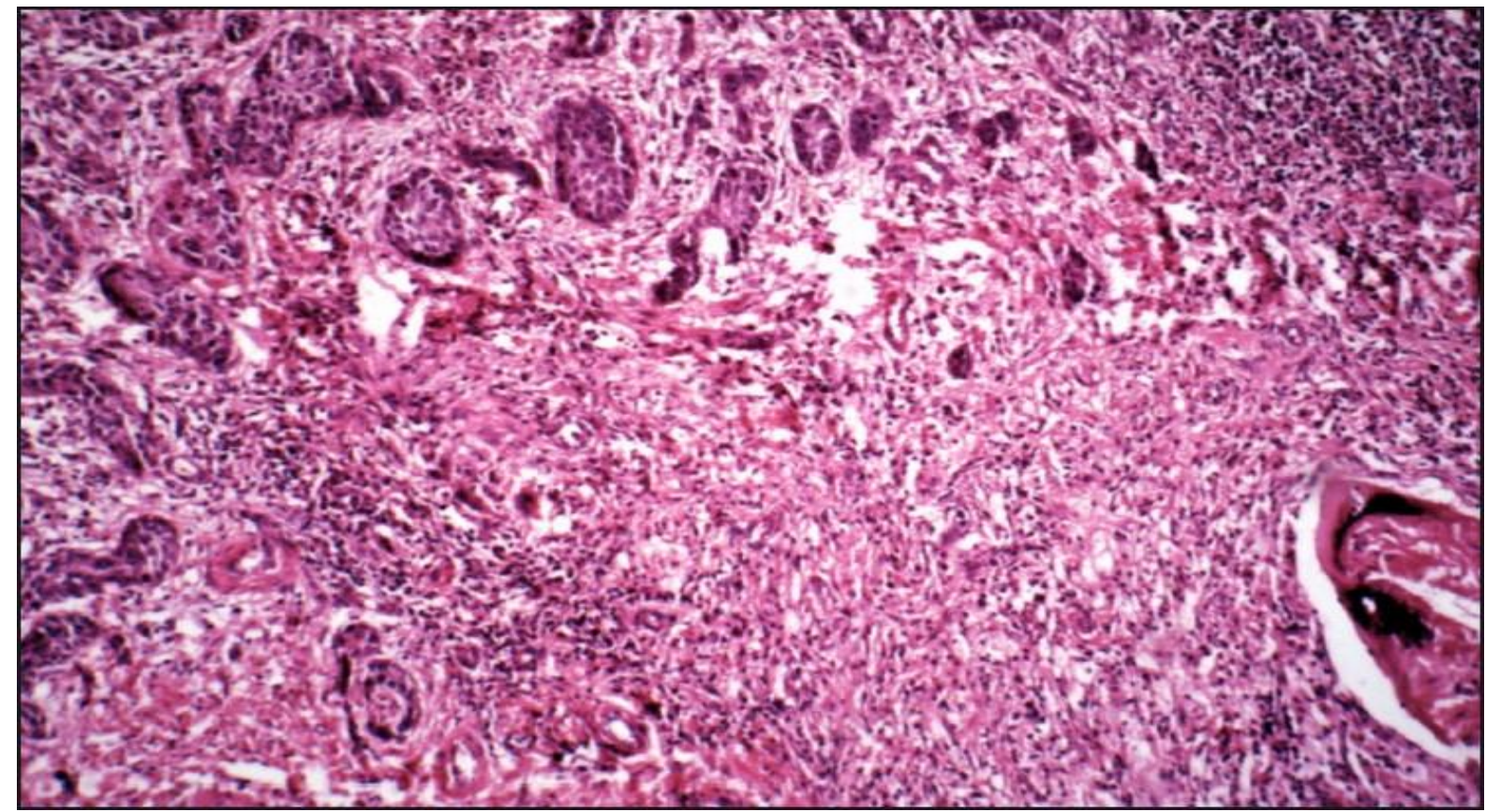

Figure 10: Photomicrograph revealing squamous cell carcinoma along with coexistent xanthogranulomatous pyelonephritis in the adjacent renal parenchyma ( $\mathrm{H}$ and E, 20x). Reproduced from: [9] Mardi K, Kaushal V, Sharma V. Rare coexistence of keratinising squamous cell carcinoma with xanthogranulomatous pyelonephritis in the same kidney: Report of two cases. Journal of Cancer Research and Therapeutics. 2010; 6(3): 339 - 341 DOI: 10.4103/0973-1482.73351http://www.cancerjournal.net/article.asp?issn=0973-

1482; year $=2010 ;$ volume $=6$;issue $=3 ;$ spage $=339$; epage $=341$; aulast $=$ Mardi \# Accessed 2019 Dec04] under copyright (C) 2010, Wolters Kluwer Medknow Publications This article is available under the terms of the Creative Commons Attribution-NonCommercial-ShareAlike License (CC BY-NC-SA), which permits non-commercial use, distribution and reproduction in any medium, provided the original work is properly cited.

Rosevear et al. [10] reported a 49-year-old man who had a 1-month history of worsening chest pain who was found to have elevated troponins but no changes upon electrocardiogram. He had a CT angiogram which showed a $7 \mathrm{~cm} \times 5 \mathrm{~cm}$ mass within his right kidney as well as multiple $1 \mathrm{~cm}$ bilateral spiculated pulmonary lesions that were suspicious for metastases. He had another CT scan one month later which showed that the kidney lesion had decreased in size to $5 \mathrm{~cm} \times 4.5 \mathrm{~cm}$. He was treated for coronary artery disease by coronary artery stenting. He was assessed by the Urology team 3 months later when he was asymptomatic and he had stated that he had had one episode of visible haematuria one year earlier which was attributed to kidney stone in the absence of renal colic and no investigation was undertaken. However; he did state that he had lost 40 pounds of weight unintentionally over the preceding 6 months. He next had a CT scan which did demonstrate that the kidney lesion had decreased with regard to size to $4 \mathrm{~cm} \times 3.8 \mathrm{~cm}$ and that majority of the pulmonary lesions, but not all of them, had resolved. A new lesion that measured 2.5 $\mathrm{cm} \times 2 \mathrm{~cm}$ with low-attenuation was found in his right renal vein which had extended into his inferior vena cava (IVC) that was consistent with a thrombus was demonstrated on the CT scan (see figure 11) and this was confirmed upon MRI scanning (see figure 12). He underwent exploration of the renal mass and during the procedure, a firm area was appreciated posterior to the IVC and the right renal vein. No freely mobile thrombus within the renal 
vein and inferior vena cava (IVC) could be palpated. An intra-operative ultrasound scan was undertaken which demonstrated that the mass was adherent to the inner posterior wall of the IVC and the renal vein and that the mass was not freely mobile within the IVC and renal vein. The mass could be followed in the renal vein into the right kidney. A right nephrectomy was undertaken leaving the IVC intact in order not to undertake insertion of a large vascular graft. Frozen section examination of the nephrectomy specimen revealed xanthogranulomatous pyelonephritis which had involved the right renal vein. Pursuant to discussions with the vascular surgeons the IVC thrombus was left intact. The final pathology examination of the nephrectomy specimen revealed a $3.7 \mathrm{~cm}$ clear cell Fuhrman grade III renal cell carcinoma of the right kidney (pT1a, as illustrated in figures 13 and 14). He had a follow-up CT scan at his 6-months follow-up which revealed a stable mass within his IVC. The exact nature of the pulmonary lesions had remained unknown even though they had decreased in size. Given the early stage of the right renal tumour and the decreasing size of the lesions, the authors were of the opinion that the pulmonary and IVC lesions were infectious in nature and they planned to follow them up to access their progress. Rosevear et al. [9] stated that focal or segmental xanthogranulomatous pyelonephritis tends to be more often confused with other pathologies in view of the fact that it often does lack the hydronephrosis or stone burden which could be a clue towards its correct diagnosis. They additionally iterated that ruling out cancer in their reported case would not have been possible preoperatively and that surgical operation was prudent. Rosevear et al. [10] made the following conclusions:

- Their reported rare case does highlight the need for careful intra-operative evaluation of unexpected findings as well as it does serve as a reminder of the need to exclude XGP in the differential diagnosis of renal cell carcinoma (RCC).

- In the era of modern radiology imaging XGP does remain a "great imitator" of renal cell carcinoma (RCC), even within the setting of renal vein and inferior vena cava (IVC) thrombus.
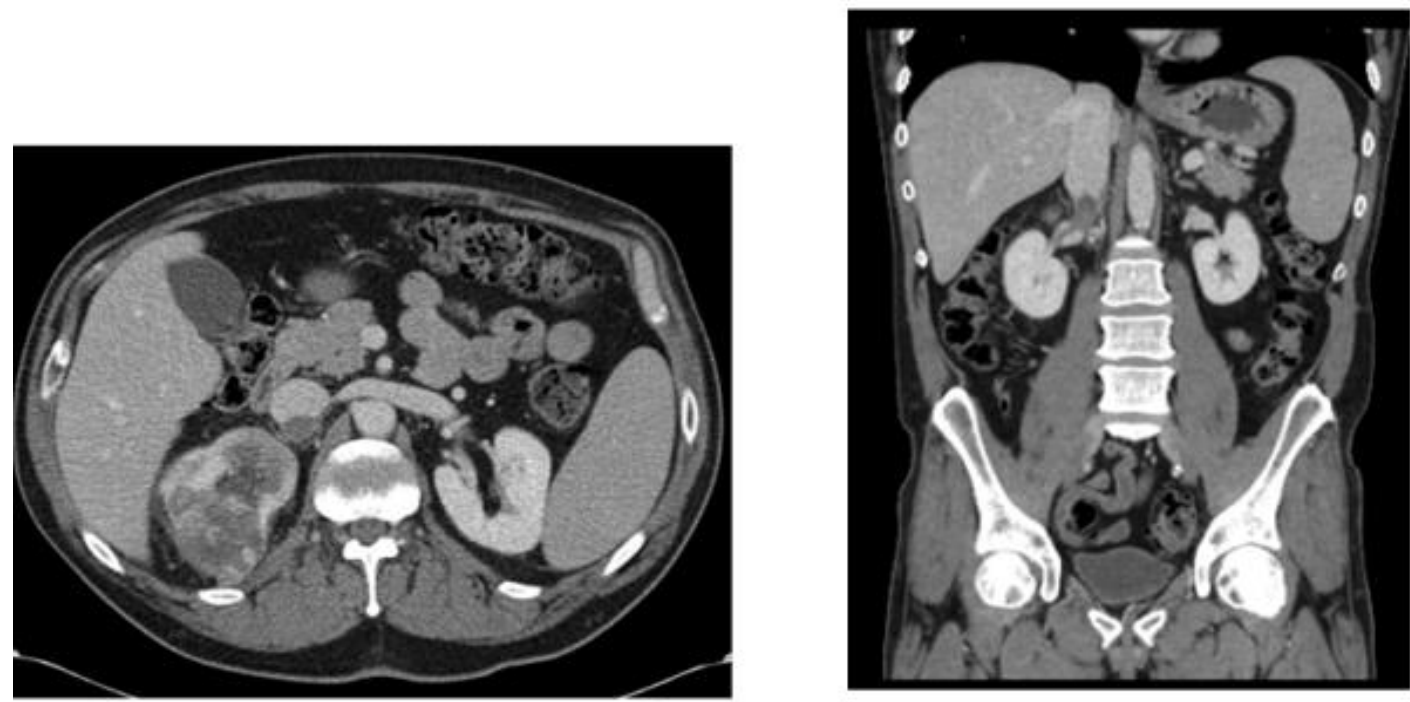

Figure 11: Axial (left) and coronal (right) CT images of the right kidney showing a midportion renal mass and tumor thrombus in the IVC. Reproduced from: [10] Rosevear H M, Meier M M, Gallagher B L, Joudi F N. Surgically 
Discovered Xanthogranulomatous Pyelonephritis Invading Inferior Vena Cava with Coexisting Renal Cell Carcinoma. The Scientific World Journal 2009; 9: 5 - $9 . \quad$ Dx.doi.org/10.1100/tsw.2009.6 https://www.hindawi.com/journals/tswj/2009/108083/abs/ http://http://downloads.hindawi.com/journals/tswi/2009/108083.pdf Accessed 2019 Dec 04 under copyright (C) 2009 Henry M Rosevear et al. and copyright at Hindawi All Hindawi Journals are published Open Access. This means all articles are immediately available free-of-charge upon publication. The articles in Hindawi Journals can be downloaded, shared, and reused without restriction, as long as the original authors are properly cited.

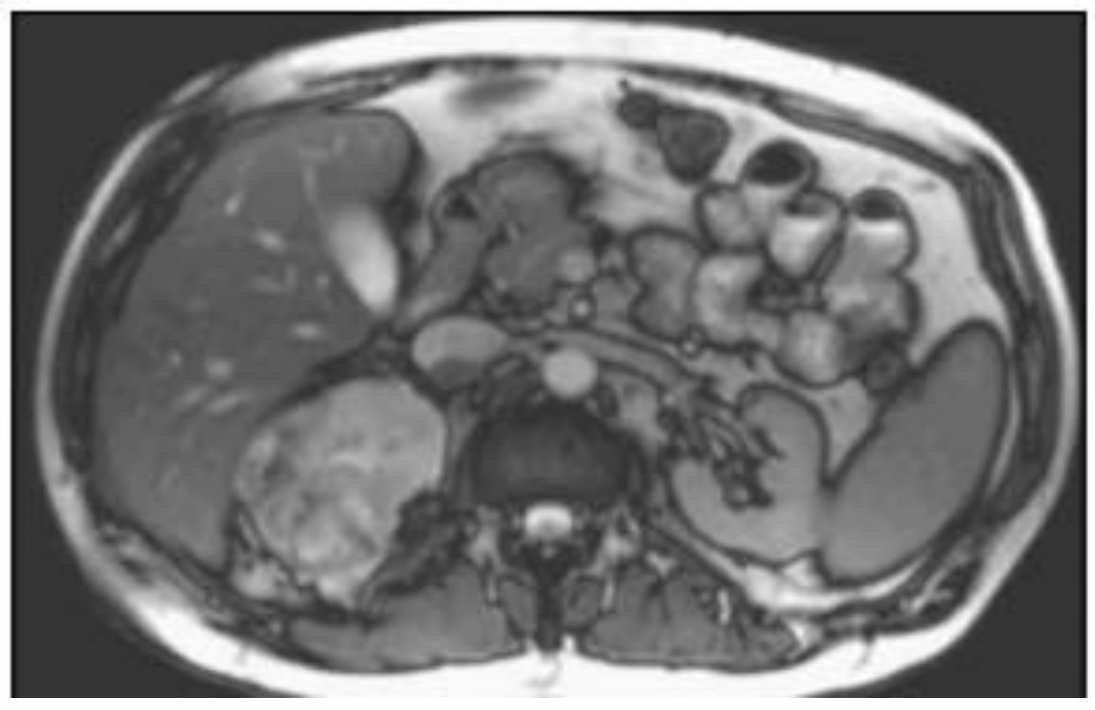

Figure 12: Axial MRI image of the right kidney demonstrating a mass in the midpole region and a thrombus in the IVC. Reproduced from: [10] Rosevear H M, Meier M M, Gallagher B L, Joudi F N. Surgically Discovered Xanthogranulomatous Pyelonephritis Invading Inferior Vena Cava with Coexisting Renal Cell Carcinoma. The $\begin{array}{lllllll}\text { Scientific World Journal 2009; } & \text { 9: } 5 & - & 9 . & \text { Dx.doi.org/10.1100/tsw.2009.6 }\end{array}$ https://www.hindawi.com/journals/tswj/2009/108083/abs/

http://http://downloads.hindawi.com/journals/tswj/2009/108083.pdf Accessed 2019 Dec 04 under copyright (C) 2009 Henry M Rosevear et al. and copyright at Hindawi All Hindawi Journals are published Open Access. This means all articles are immediately available free-of-charge upon publication. The articles in Hindawi Journals can be downloaded, shared, and reused without restriction, as long as the original authors are properly cited.

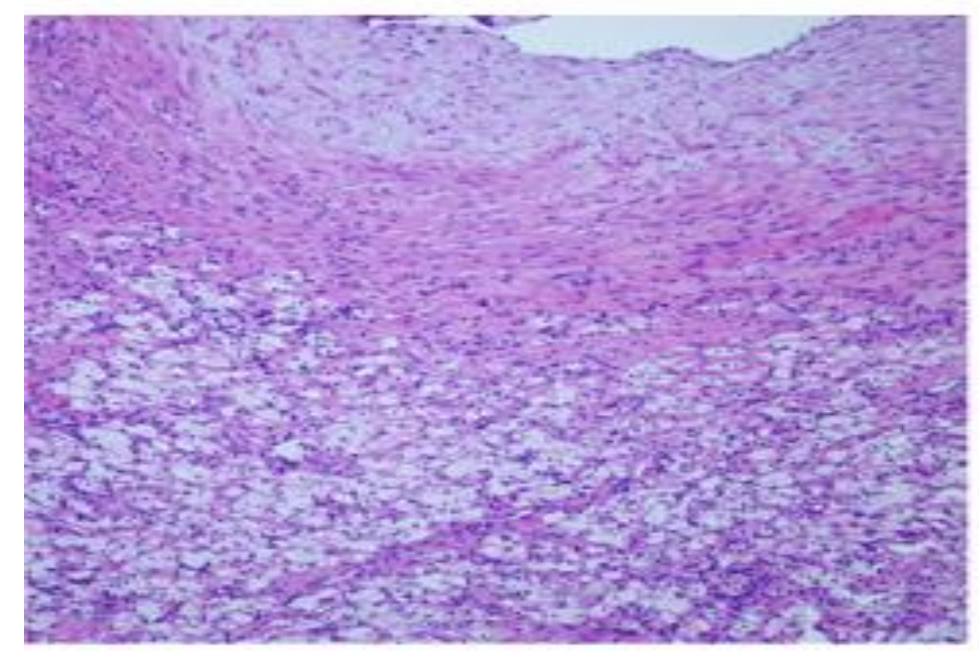

Figure 13: Histology showing XGP with characteristic xanthoma cells present surrounding and invading the IVC. Reproduced from: [10] Rosevear H M, Meier M M, Gallagher B L, Joudi F N. Surgically Discovered 
Xanthogranulomatous Pyelonephritis Invading Inferior Vena Cava with Coexisting Renal Cell Carcinoma. The $\begin{array}{llllll}\text { Scientific World Journal 2009; } \quad 9: \quad 5 \quad & - & 9 . & \text { Dx.doi.org/10.1100/tsw.2009.6 }\end{array}$ https://www.hindawi.com/journals/tswj/2009/108083/abs/

http://http://downloads.hindawi.com/journals/tswj/2009/108083.pdf Accessed 2019 Dec 04under copyright (C) 2009 Henry M Rosevear et al. and copyright at Hindawi All Hindawi Journals are published Open Access. This means all articles are immediately available free-of-charge upon publication. The articles in Hindawi Journals can be downloaded, shared, and reused without restriction, as long as the original authors are properly cited.

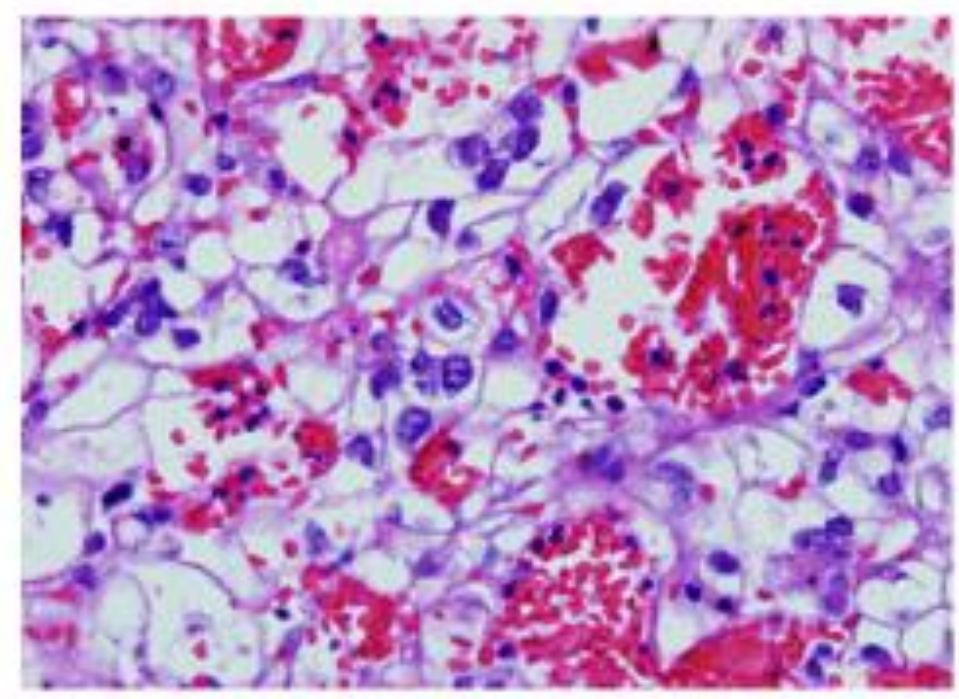

Figure 14: Histology showing conventional type clear cell RCC Fuhrman nuclear grade III with extensive vascularity. Reproduced from: [10] Rosevear H M, Meier M M, Gallagher B L, Joudi F N. Surgically Discovered Xanthogranulomatous Pyelonephritis Invading Inferior Vena Cava with Coexisting Renal Cell Carcinoma. The

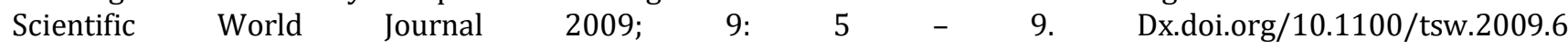
https://www.hindawi.com/journals/tswj/2009/108083/abs/

http://http://downloads.hindawi.com/journals/tswj/2009/108083.pdf Accessed 2019 Dec 04 under copyright (C) 2009 Henry M Rosevear et al. and copyright at Hindawi All Hindawi Journals are published Open Access. This means all articles are immediately available free-of-charge upon publication. The articles in Hindawi Journals can be downloaded, shared, and reused without restriction, as long as the original authors are properly cited.

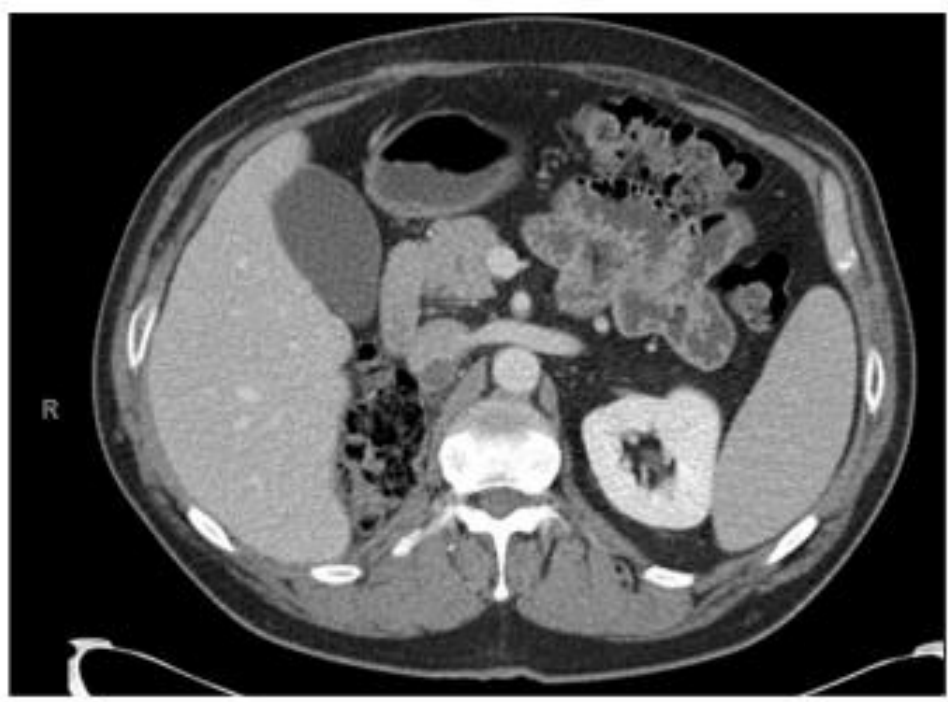


Figure 15: CT 6 months post-surgery showing a stable non-enhancing mass posterior to the IVC. Reproduced from: [10] Rosevear H M, Meier M M, Gallagher B L, Joudi F N. Surgically Discovered Xanthogranulomatous Pyelonephritis Invading Inferior Vena Cava with Coexisting Renal Cell Carcinoma. The Scientific World Journal 2009; 9: 5 - 9. Dx.doi.org/10.1100/tsw.2009.6 https://www.hindawi.com/journals/tswi/2009/108083/abs/ http://http://downloads.hindawi.com/journals/tswj/2009/108083.pdf Accessed 2019 Dec 04under copyright (C) 2009 Henry M Rosevear et al. and copyright at Hindawi All Hindawi Journals are published Open Access. This means all articles are immediately available free-of-charge upon publication. The articles in Hindawi Journals can be downloaded, shared, and reused without restriction, as long as the original authors are properly cited.

Pegas et al. [36] reported a 51-year-old lady who had presented with pain in the left upper quadrant of her abdomen over the preceding one month. She had a computed tomography (CT) scan of her abdomen and pelvis which showed a nodular tumour-like lesion within the upper pole of her left kidney. She underwent left upper pole partial nephrectomy. Macroscopic examination of the specimen showed a poorly circumscribed yellow-soft nodule with central degeneration that measured $3.0 \mathrm{~cm} \times 2.0 \mathrm{~cm} \times 2.0 \mathrm{~cm}$. Microscopic examination of the specimen showed a suppurative chronic interstitial nephritis associated with a lymphoid and neutrophil infiltrate, central necrotic zone that were encompassed by foamy macrophages as well as multi-nucleated giant cells, atrophy of the tubules, periglomerular fibrosis as well as global glomerular sclerosis. The inflammatory process was noted to have extended into the medulla and into the perinephric fat. Many spherical laminated rings that had been admixed with macrophages (see figure 16) were visualised next to the central necrotic zone. The ring-like laminated structures did mimic psammoma bodies or an ovum of a parasite. The rings did have an amorphous, central core which was encompassed by a double layered wall, that was accentuated with PAS (see figure 17), and stained negatively with von Kossa, Grocott, as well as trichome stains. The rings under polarized light were observed to be nonbirefringent. Based upon the pathology examination features of the kidney lesion a diagnosis of xanthogranulomatous pyelonephritis with Liesegang rings was made. Long-term follow-up data was not available. Pegas et al. [36] stated the following:

- Liesegang is an in vitro physicochemical precipitating process which was first described by German biochemist Ralph Eduard Liesegang, a German who was born in Elberfeld and who did develop the methods of capillary analysis, a precursor of chromatography [37].

- The exact composition of the Liesegang rings has not been fully clarified; nevertheless, immunohistochemistry and histochemical stains for calcium (von Kossa), iron, mucopolysaccharide, amyloid glycogen, keratin, and epithelial membrane antigen (EMA) tend to be negative. Special stains, radiographic analysis, or scanning electron microscopy did demonstrate that some Liesegang rings did contain iron, silicon, and sulphur. According to iterations of Tuur et al. [38] Liesegang rings contain Calcium ( $\mathrm{Ca}++$ ) apart from other inorganic anions, organic polycations and polyanions.

- Liesegang rings are an uncommon histological finding of some inflammatory diseases like Xanthogranulomatous pyelonephritis.

- The pathogenesis of Liesegang rings has remained unclear; nevertheless, it is important to be able to recognise the typifying features of Liesegang rings in order to avoid mistaking these rings for parasites. 


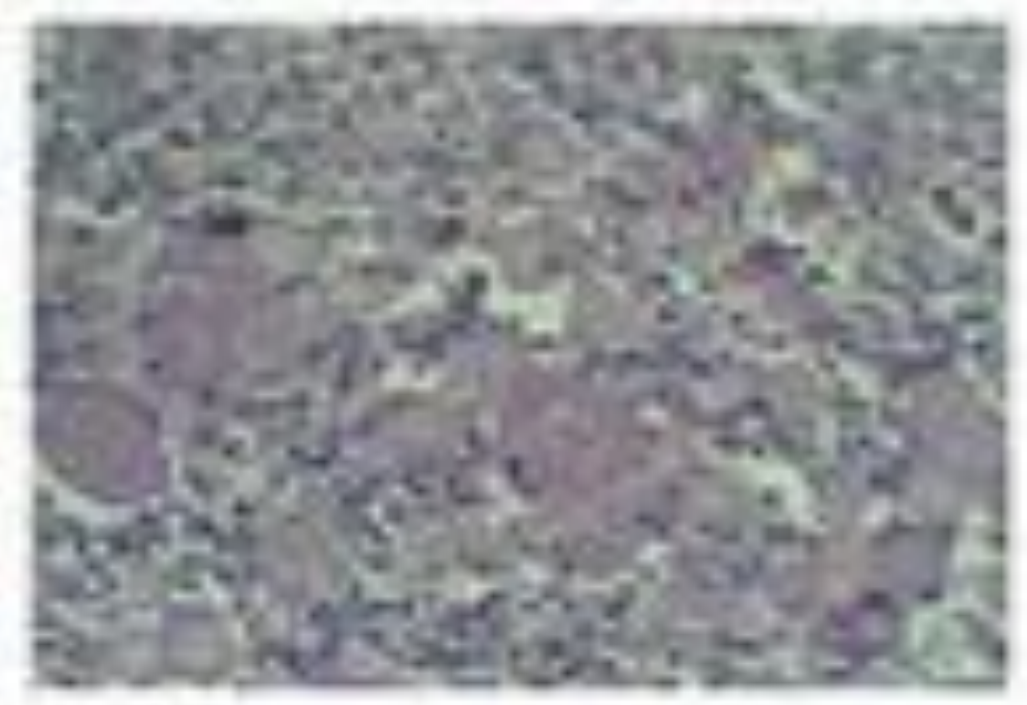

Figure 16: Acellular laminated ring-like structures intermingled with macrophages (Hematoxylin-eosin-100x). Reproduced from: [36] Pegas K L, Edelweiss M I, Cambruzzi E, Zettler G. Liesegang Rings in Xanthogranulomatous Pyelonephritis: A Case Report. Pathology Research International. 2010;Article ID 602523, 3 pages http://dx.doi.org/10.4061/2010/602523 https://www.hindawi.com/journals/pri/2010/602523/ Accessed 2019 Dec 04 under copyright (C) 2010 Karla Laís Pegas et al. This is an open access article distributed under the Creative Commons Attribution License, which permits unrestricted use, distribution, and reproduction in any medium, provided the original work is properly cited.

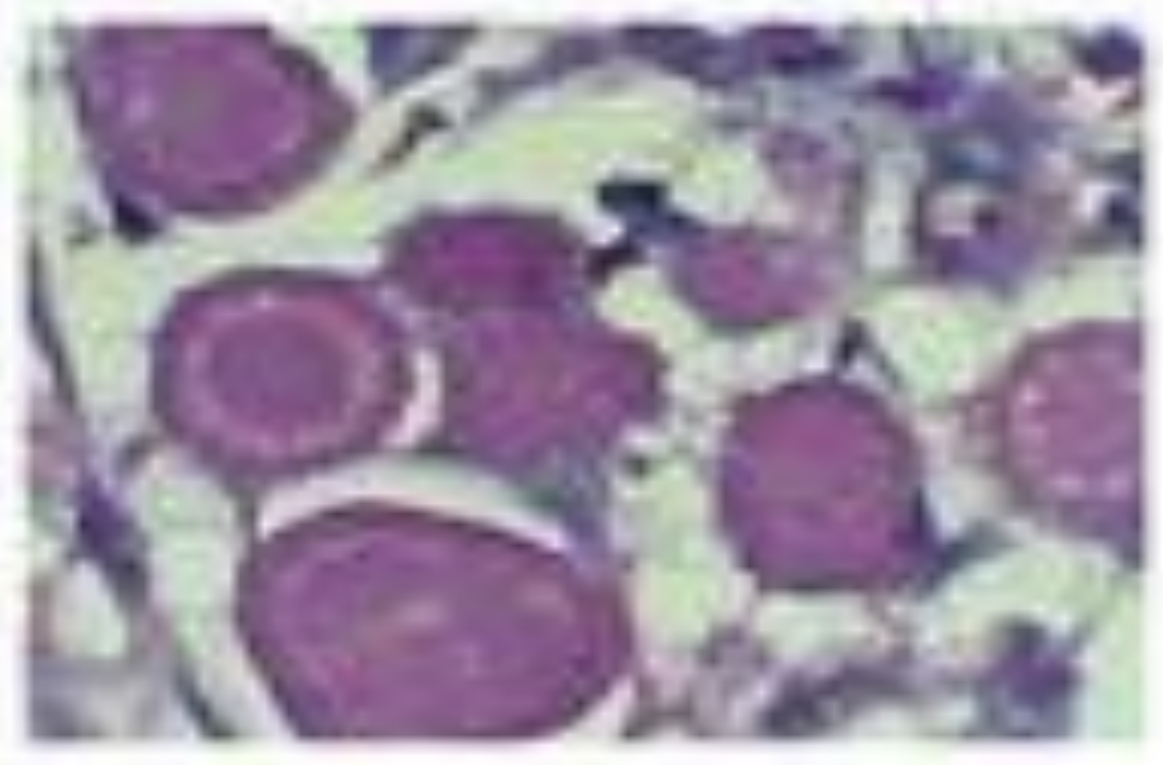

Figure 17: Liesegang rings are positive to PAS stains (400x). Reproduced from: [36] [Pegas K L, Edelweiss M I, Cambruzzi E, Zettler G. Liesegang Rings in Xanthogranulomatous Pyelonephritis: A Case Report. Pathology Research International. 2010;Article ID 602523, 3 pages http://dx.doi.org/10.4061/2010/602523 https://www.hindawi.com/journals/pri/2010/602523/ Accessed 2019 Dec 04 under copyright (C) 2010 Karla Laís Pegas et al. This is an open access article distributed under the Creative Commons Attribution License, which 
permits unrestricted use, distribution, and reproduction in any medium, provided the original work is properly cited.

Ballentine et al. [39] reported the case of xanthogranulomatous pyelonephritis in a 58-yearold lady who had manifested with abdominal pain, haematuria, and radiating left loin pain. She had CT scan of her abdomen and pelvis which revealed a lesion that was reported to be consistent with perirenal haemorrhage that was abutting a fatcontaining left renal mass. She was taken to theatre

- The traditional approach to xanthogranulomatous pyelonephritis has been radical nephrectomy, even though a nephron-sparing approach had been reported in the treatment of focal cases of XGP [13]; [40]; [41].

- Conservative treatment of XGP had been achieved with utilization of parenteral antibiotic treatment or with a combination of oral and parenteral treatment which could be supplemented with drainage of the urinary tract and or abscess [42]; [43]; [44].

- Conservative treatment had proven to be successful in the treatment of renal allograft patients who have XGP [45].

- Nevertheless, conservative treatment would tend not to be appropriate for patients who have stage III or diffuse XGP, as may be observed in many patients at the time of the initial diagnosis.

- Nephron-sparing treatment had been attempted with success with regard to cases of multifocal XGP which is a distinct entity from diffuse XGP.

- Considering that XGP had often been diagnosed firstly based upon pathology examination of nephrectomy specimens, the decision with regard to the choice of treatment had usually been based upon a presumptive diagnosis in which radical nephrectomy could be more appropriate.

- All four previous reports of xanthogranulomatous pyelonephritis that and she underwent left partial nephrectomy. The pathology examination features of the specimen showed features that were diagnosed as xanthogranulomatous pyelonephritis. She had remained well with no complications from the disease at her 8-month post-operative follow-up. Ballentine et al. [39] stated the following:

manifested with spontaneous renal haemorrhage had been managed by radical nephrectomy. Their reported case of nephron-sparing surgery for XGP that manifested with spontaneous renal haemorrhage was the first to be reported in the literature.

- Their management decision of nephronsparing surgery had been facilitated by a pre-operative differential diagnosis which heavily had weighed on angiomyolipoma of the kidney as the cause of the spontaneous renal haemorrhage. Prior to their surgical procedure, their approach to cases that involve a large XGP lesion would have not been likely to include a nephron-sparing approach, even though they were happy to report such an approach to be certainly technically feasible.

- Nephron-sparing surgery should always be considered as a possibility even with regard to such difficult cases of XGP.

\section{Conclusions}

- Xanthogranulomatous pyelonephritis (XGP) is a rare disease with less than 500 cases reported in the literature.

- XGP does present with non-specific symptoms that mimic many diseases and its diagnosis would require a high index of suspicion.

- Most cases of XGP had been treated successfully by radical nephrectomy in combination with utilization of antibiotics 
and the diagnosis was made upon pathology examination of the nephrectomy specimens post-operatively.

- Few cases of focal XGP have been successfully treated by means of nervesparing partial nephrectomy plus utilization of antibiotic treatment.

- Very few cases of XGP have been treated by utilization of conservative management with parenteral antibiotics treatment or a with a combination of oral and parenteral treatment which had been supplanted with drainage of the urinary tract and or abscess; nevertheless, if this conservative approach is undertaken it would require that patients who have staghorn calculi would need to have subsequent treatment by means of (a) per-cutaneous nephrolithotomy, uretero-renoscopy plus lithotripsy or (c) extra-corporeal shock wave lithotripsy which would on the whole take a long time to complete full treatment for such selected patients.

\section{Acknowledgements}

- Journal of Medical Case Reports for granting permission for reproduction of contents and figures from their journal article under copyright Open Access This article is distributed under the terms of the Creative Commons Attribution 4.0 International License

(http://creativecommons.org/licenses/by/ 4.0/), which permits unrestricted use, distribution, and reproduction in any medium, provided you give appropriate credit to the original author(s) and the source, provide a link to the Creative Commons license, and indicate if changes were made. The Creative Commons Public Domain Dedication Waiver (http://creativecommons.org/publicdomain /zero/1.0/) applies to the data made available in this article, unless otherwise stated.

- Case Reports in Radiology and Hindawi Publishing Company Limited for granting permission for reproduction of contents and figures from their journal article under copyright (C) 2018 Ahmad Enshaei et al. This is an open access article distributed under the Creative Commons Attribution License, which permits unrestricted use, distribution, and reproduction in any medium, provided the original work is properly cited.

- Brazilian Journal of Infectious Diseases for granting permission for reproduction of contents and figures from their journal article under The Creative Commons Attribution License (CC BY-NC-ND), All the contents of this journal, except where otherwise noted, is licensed under a Creative Commons Attribution License.

- Journal of Cancer Research and Therapeutics and Wolter Kluwer Medknow Publications for granting permission for reproduction of contents and figures from their journal article under copyright (C) 2010, Wolters Kluwer Medknow Publications This article is available under the terms of the Creative Commons Attribution-NonCommercial-ShareAlike License (CC BY-NC-SA), which permits noncommercial use, distribution and reproduction in any medium, provided the original work is properly cited.

- The Scientific World Journal and the Hindawi Journals Publishing Limited for granting permission for reproduction of contents and figures from their Journal article under copyright (C) 2009 Henry M Rosevear et al. and copyright at Hindawi All Hindawi Journals are published Open Access. This means all articles are immediately available free-of-charge upon publication. The articles in Hindawi Journals 
can be downloaded, shared, and reused without restriction, as long as the original authors are properly cited.

- Pathology Research International and Hindawi Publishing Company for granting permission for reproduction of contents and figures from their Journal article under copyright (C) 2010 Karla Laís Pegas et al. This is an open access article distributed under the Creative Commons Attribution License, which permits unrestricted use, distribution, and reproduction in any medium, provided the original work is properly cited.

\section{References}

1. Schahengaufer F. Uber eigentumlich staphylomykosender neiven und des pararenalen bindegewebes. Frankfurt Z Pathol 1916; 19: 139 - 148.

2. Deem S G, Schwartz B F, Mobley J D, Xanthogranulomatous Medscape 2017 Jan 23; https://emedicine.medscape.com/article/205 0430-overview

3. Caliskan S, Ozsoy E, Kaba S, Koca O, Ozturk M I. Xanthogranulomatous Pyelonephritis. Arch Iran Med. 2016 Oct; 19(10): 712 - 714.

4. Sangle N, Kidney nontumor Bacterial infections Xanthogranulomatous pyelonephritis PathologyOutlines.com Topic completed 2014 Aug 04; Revised 2019 Mar 12. http://www.pathologyoutlines.com/topickidn eyxantho.html Accessed $2019 \mathrm{Dec} 03$

5. Li L, Parwani A V. Xanthogranulomatous pyelonephritis Arch Pathol Lab Med 2011 May; $135(5): \quad 671 \quad-\quad 674$ https://www.archivesofpathology.org/doi/ful l/10.1043/2009-0769-RSR.1

6. Quinn F M, Dick A C, Corbally M T, McDermott M B, Guiney E J. Xanthogranulomatous pyelonephritis in childhood. Arch Dis Child. 1999 Dec; 81(6): 483 - 486 https://adc.bmj.com/content/archdischild/81 16/483.full.pdf
7. Kuo $C \mathrm{C}, \mathrm{Wu} C \mathrm{~F}$, Huang $\mathrm{C} C$, Lee $\mathrm{Y}$ J, Lin $\mathrm{W} C$, Tsai C W, Wu V C, Chen Y M, Wu M S, Chu T S, Wu K D. Xanthogranulomatous pyelonephritis: critical analysis of 30 patients. Int Urol. Nephrol 2011 Mar; 43(1): 15 - 22. DOI: 10.1007/s11255-010-9778-8

https://www.ncbi.nlm.nih.gov/pubmed/2054 4282 Accessed 2019 Dec 03

8. Gasmi M, Jemai R, Fitouri F, Ben Slama A, Sahli $S$, Hamzaoui M. Xanthogranulomatous pyelonephritis in childhood: diagnosis difficulties and success of conservative treatment. Tunis Med. 2010 Jun; 88(6): 427 429.

https://www.ncbi.nlm.nih.gov/pubmed/2051 7855 Accessed 2019 Dec 03.

9. Mardi K, Kaushal V, Sharma V. Rare coexistence of keratinizing squamous cell carcinoma with xanthogranulomatous pyelonephritis in the same kidney: report of two cases. J Cancer Res Ther. 2010 Jul-Sep; 6(3): 339 - 341 DOI: 10.4103/09731482.73351

https://www.ncbi.nlm.nih.gov/pubmed/2111 9270 Accessed 2019 Dec 03

10. Roseveaer H M, Meier M, M, Gallagher B, L, Joudi F N. Surgically discovered xanthogranulomatous pyelonephritis invading inferior vena cava with coexisting renal cell carcinoma. Scientific World Journal 2009 Jan; 18(9): 5 - 9. DOI: $10.1100 /$ tsw.2009.6 https://www.ncbi.nlm.nih.gov/pubmed/1915 1892 Accessed 2019 Dec 03

11. Tiu C M, Chou Y-H, Chiou H-J Lo C-B, Yang J-Y, Chen K K, Hsu M-H, Wang J-H, Su Y-G, Chang C $\mathrm{Y}, \mathrm{Yu} \mathrm{C}$. Sonographic features of xanthogranulomatous pyelonephritis. J Clin Ultrasound 2001;29: $279 \quad-\quad 285$ https://doi.org/10.1002/jcu.1034 https://www.onlinelibrary.wiley.com/doi/abs $\angle 10.1002 /$ icu. 1034

12. Rajesh A, Jakanani G, Mayer N, Mulcahy K. Computed Tomography Findings in Xanthogranulomatous Pyelonephritis Journal of Clinical Imaging Science 2011; 1:45 DOI: 10.4103/2156-7514.84323

https://clinicalimagingscience.org/computed- 
tomography-findings-in-

xanthogranulomatous-pyelonephritis/

13. Peréz L M, Thrasher J B, Anderson E E, Successful management of bilateral xanthogranulomatouspyelonephritis by bilateral partial nephrectomy. J Urol. 1993; 149(1): $\quad 100 \quad-102$ https://doi.org/10.1016/S00225347(17)36011-1

https://www.auajournals.org/doi/10.1016/S 0022-5347\%2817\%2936011-1

14. Romero F R, Pilati R, Caboclo M F, Silva Ade P, Cravo M A, Brenny Filho T. Renal replacement lipomatosis and xanthogranulomatous pyelonephritis: differential diagnosis. Rev Assoc Med Bras (1992). 2011 May - Jun; 57(3): $\quad 262 \quad-\quad 265$. $10.1590 / \mathrm{s} 0104 / 42302011000300005$ https://www.ncbi.nlm.nih.gov/pubmed/2169 1686 Accessed 2019 Dec 03

15. Chandrakunnel J, Cunha B A, Petelin A, Katz D. Fever of unknown origin (FUO) and a renal mass: renal carcinoma, renal tuberculosis, renal malakoplakia, or xanthogranuloma pyelonephritis. Heart Lung 2012 Nov-Dec; 41(6): $606 \quad-609 . \quad$ DOI: 10.1016/j.hrtlng.2012.03.008 https://www.ncbi.nlm.nih.gov/pubmed/2265 8892 Accessed 2019 Dec 04

16. Chow J, Kabani R, Lithgow K, Sarna M A. Xanthogranulomatous pyelonephritis presenting as acute pleuritic chest pain: a case report. Journal of Medical Case Reports. 2017; 11: 101 DOI: 10.1186/s13256-017-1277-4 https://jmedicalcasereports.biomedcentral.co m/articles/10.1186/s13256-017-12774\#citeas Accessed 2019 Dec 03

17. Enshaei A, Boora A A, Taheri D, Changizi Z, Bahmani N. Focal Xanthogranulomatous Pyelonephritis with Pulmonary Lesions on the Background of Type Two Diabetes Mellitus. Case Reports in Radiology Volume 2018; Article ID 1698285,5 pages https://doi.org/10.1155/2018/1698286 https://www.hindawi.com/journals/crira/20 18/1698286/ Accessed 2019 Dec 03
18. Ramos L D, Lima M D M, de Carvalho $M$, da Silver Junior G B, Daher E D F. Emphyematous and granulomatous pyelonephritis: rare diagnosis. Brazilian Journal of Infectious Diseases. 2010 Jul-Aug; 14(4): http://dx.doi.org/10.1590/S141386702010000400011

http://www.scielo.br/scielo.php?script=sci_ar ttext\&pid=S1413-86702010000400011

Accessed 2019 Dec 04

19. Leoni A F, Luque A, Sambuelli R H, Valverde J C. Pielonefritis xantogranulomatosa associada a flora poli microbiana. Rev Panam Infectol. 2004; $6: \quad 23 \quad-\quad 27$. https://www.scopus.com/record/display.uri? eid=2-s2.070449358240\&origin=inward\&txGid=5460d1 159867d2889f5571041ed538bc

20. Punekar S V, Kinne J S, Rao S R, Madiwale C, Karhadkar S S. Xanthogranulomatous pyelonephritis presenting as emphysematous pyelonephritis: rare association. J Postgrad Med. 1999; 45(4): 125 https://www.scopus.com/record/display.uri? eid=2-s2.0$\underline{0033202863 \& \text { origin }=i n w a r d \& t x G i d=99 a 23 a 6}$ b04b943ae75fdc0e1564d13cf

21. Lim C H, Kim W B, Yon Su Kim et al. Bilateral emphysematous pyelonephritis with perirenal abscess cured by conservative therapy. J Nephrol. 2000; 13(2): 155 - 158. https://www.scopus.com/record/display.uri? eid=2-s2.0$\underline{0034112056 \& \text { origin }=\text { inward } \& \text { txGid }=6 \mathrm{e} 3 \mathrm{~d} 115}$ e21faefc4d336cbdf6ab988ad

22. Shetty $S$ et al. Emphysematous pyelonephritis. Department of Urology, W Beaumont Hospital 2006; 1: 1-10.

23. D'ippolito G, Tockechi D. Tomografic aspects of xanthogranulomatous pyelonephritis and related complications. São Paulo Med J. 1996 Jan-Feb; $114(1): 1091$ - 1096. https://www.scopus.com/record/display.uri? eid=2-s2.00029678179\&origin=inward\&txGid=ef3ba4ad fe90647765f700a620cef2d3 
24. Filho H N V, Filho W A F, Souza H A M, Leal T, Tenório A L. Pielenefrite xantogranulomatosa. J Pediatria (Rio J). 1994; 70(5): 302 - 304. http://www.jped.com.br/ArtigoDetalhe.aspx? varArtigo $=692 \&$ idioma $=p t-B R$

25. Alam A, Chander B N, Joshi D P. Xanthogranulomatous pyelonephritis: diagnosis using computer tomography. Med J. Armed Forces India 2004 Jan; 60(1): 86 - 88. https://www.scopus.com/record/display.uri? eid=2-s2.0-

\section{6\&origin=inward\&txGid=becd6a4 b44389b9ac9f000544c4a293b}

26. Quinn F J M, Dick A C, Corbally M T, McDermott M B, Guiney E J. Xanthogranulomatous pyelonephritis in childhood. Arch Dis Child 1999; 81(6): 403 - 486 https://adc.bmj.com/content/81/6/483.short

27. Eastham J, Ahlering $T$, Skinner E. Xanthogranulomatous pyelonephritis: clinical findings and surgical considerations. Urology 1994 Mar; 43(3): 295 - 299. https://www.scopus.com/record/display.uri? eid $=2$-s2.0-

0028274008\&origin $=$ inward\&txGid=afd05b04 62b385fc3445bee3032d63d8

28. Príncipe $P$, Costa L. Infeccao do tracto urinário. Rev Port Clin Geral 2005; 21: 219 - 225.

29. Hortling N, Layer G, Albers $P$, Schild H H. Xanthogranulomatous pyelonephritis with septic lung metastases and infiltration of the colon. Difficult preoperative differential pulmonary hypernephroma metastasis diagnosis. Aktuelle Radiol 1997(6); 7: 317 https://www.scopus.com/record/display.uri? eid $=2$-s2.0-

$\underline{0031264530 \& \text { origin }=\text { inward } \& \text { txGid }=48 \mathrm{c} 6442}$ ef186c6e5fd86ec6ea4a52ff5

30. al-Suleiman M H, al-Khader A A, Mousa D H, et al. Renal parenchymal malacoplakia and megalocytic interstitial nephritis: clinical and histological features. Report of two cases and review of the literature. Am J Nephrol. 1993; 13(6): $\quad 483 \quad-488$. https://www.scopus.com/record/display.uri? eid=2-s2.0-
0027738435\&origin=inward\&txGid=6b55bc0f 2b17e9ebdfee203917770d30

31. McGorry D M, Kroser J, Taylor L T, Howard Lewis H, Gabale D. Emphysematous Pyelonephritis Presenting as an Acute Abdomen. Infect Urol. 1999; 12: 162 - 165.

32. Kim J C. US and CT findings of xanthogranulomatous pyelonephritis. Clin Imaging 2001; 25(2): $118 \quad-121$ https://www.scopus.com/record/display.uri? eid=2-s2.00034908718\&origin=inward\&txGid=beba7ed d03369b1dadcb797916f4c0a3

33. Jain S K, Agarwal $\mathrm{N}$, Chaturvedi $\mathrm{S}$ K. Emphysematous pyelonephritis: a rare presentation. J Postgrad Med 2000; 46: 31 32.

34. Dhingra K K, Sukard S, Shyama J. Rare coexistence of keratinizing squamous metaplasia with xanthogranulomatous pyelonephritis: Report of a case with the role of immunocytochemistry in the differential diagnosis. Acta Cytol 2007 Jan - Feb; 51(1): 92

$$
\text { - }
$$

https://www.ncbi.nlm.nih.gov/pubmed/1732 $\underline{8505}$

35. Pitts J C, Peterson N E, Conley M C. Calcified functionless kidney in a 51 year old man. J Urol.1981 Mar; 125(3): 398 - 401 DOI: 10.1016/s0022-5347(17)55050-8

https://www.ncbi.nlm.nih.gov/pubmed/7206 $\underline{093}$

36. Pegas K L, Edelweiss M I, Cambruzzi E, Zettler G. Liesegang Rings in Xanthogranulomatous Pyelonephritis: A Case Report. Pathology Research International. 2010;Article ID 602523, 3 pages http://dx.doi.org/10.4061/2010/602523 https://www.hindawi.com/journals/pri/2010 1602523/Accessed 2019 Dec 04

37. Liesegang R E. Über einige eigenschaften von gallerten Naturwissensch Wochenschr 1896; 11: 353 - 362.

38. Tuur S M, Nelson A M, Gibson D W, et al. Liesegang rings in tissue: how to distinguish Liesegang rings from the giant kidney worm, Dioctophyma renale American Journal of 
Surgical Pathology 1987 Aug; 11(8): 598 - 605 https://www.ncbi.nlm.nih.gov/pubmed/2956 $\underline{899}$

39. Ballentine W K, Vilson F, Dyer R B, Mirzazadeh M. Nephron-sparing management of Xanthogranulomatouspyelonephritis presenting as spontaneous renal haemorrhage: a case report and literature review. BMC Urology 2018; 18: 57 DOI: 10.1186/s12894-018-0354-3

https://bmcurol.biomedcentral.com/articles/ 10.1186/s12894-018-0354-3

40. Osca J M, Peiro M J, Rodrigo M, MartinezJabaloyas J M, Jimenez-Cruz J F. Focal xanthogranulomatouspyelonephritis: partial nephrectomy as definitive treatment. Eur Urol. 1997; $32: \quad 375 \quad-\quad 379$ https://reference.medscape.com/medline/abs tract/9358230

41. Shinde S, Kandpal D K, Chowdhary S K. Focal xanthogranulomatous pyelonephritis presenting as renal tumor. Indian J Nephrol 2013 Jan-Feb; 23(1): 76 - 77 DOI: 10.4103/0971-4065.107219

https://www.ncbi.nlm.nih.gov/pmc/articles/P MC3621249/

42. Chlif $M$, Chakroun $M$, Ben Rhouma $S$, Ben Chehida M A, Sellami A, Gargouri M M, Noura Y. Xanthogranulomatous pyelonephritis presenting as a pseudo tumour. Can Urol. Assoc J. 2016 Jan-Feb; 10(1-2): E36 -E 40 DOI: 10.5489/cuaj.3225

https://www.ncbi.nlm.nih.gov/pmc/articles/P MC4729574/

43. Friedl A, Tuerk C, Schima W, Broessner C. Xanthogranulomatous pyelonephritis with staghorn Calculus, acute gangrenous appendicitis and enterocolitis: a multidisciplinary challenge of kidneypreserving conservative therapy. Curr Urol. 2015 Sep; 8(3): 162 - 165 DOI: $10.1159 / 000365709$.

https://www.ncbi.nlm.nih.gov/pubmed/2688 9137

44. Brown $\mathrm{P} S$, Dodson $\mathrm{M}$, Weintrub $\mathrm{P} S$. Xanthogranulomatous pyelonephritis: report of nonsurgical management of a case and review of the literature. Clin Infect. Dis. 1996 Feb; 22(2): 308 - 314. DOI: https://doi.org/10.1093/clinids/22.2.308 https://academic.oup.com/cid/article/22/2/3 $\underline{08 / 279733}$

45. Elkhammas E A, Mutabagani K H, Sedmak D D, Tesi R J, Henry M L, Ferguson $R$ M. Xanthogranulomatous pyelonephritis in renal allografts: report of 2 cases. J Urol. 1994 Jan; 151(1): 127 128.

https://doi.org/10.1016/S00225347(17)34890-5

https://www.auajournals.org/doi/10.1016/S 0022-5347\%2817\%2934890-5

How to cite this Article: * Anthony Kodzo-Grey Venyo; Xanthogranulomatous Pyelonephritis A Review and Update of the Literature

Int. Res. Med. Health Sci., 2019; (2-6): 44-73

Source of Support: Nil, Conflict of Interest: None declared.

Received: 05-12-2019; Revision: 20-12-2019; Accepted: 23-12-2019 